\title{
Cults of personality, preference falsification, and the dictator's dilemma
}

\author{
Charles Crabtree ${ }^{\S}$, Holger L. Kern ${ }^{\dagger}$, and David A. Siegel ${ }^{\ddagger}$
}

\begin{abstract}
We provide a novel rational explanation for why cults of personality exist: they solve the dictator's adverse selection problem in assigning subordinates to roles within the regime. Participation in a cult of personality is psychologically costly whenever it involves preference falsification, with the costs varying across individuals. Importantly, low psychological costs of preference falsification are correlated with traits the dictator values, such as unscrupulousness and ruthlessness, which we collectively term disposition-based competence. Under a wide variety of circumstances, this correlation makes participation in cults of personality informative from the dictator's point of view, allowing him to hire loyal and competent subordinates for the most important regime positions. In contrast to earlier formal work, our model implies that dictators can use cults of personality to avoid the loyalty-competence trade-off when promoting subordinates.
\end{abstract}

We thank Quintin Beazer, Jens Grosser, Timur Kuran, Andrew Little, Eddy Malesky, Melanie Manion, Arturas Rozenas, Rory Truex, Nils Weidmann, and participants at the 2017 MPSA Conference and the 2017 ESTA workshop at Konstanz University for their very helpful feedback.

$\S$ PhD cand., Department of Political Science, University of Michigan.

$\dagger$ Assistant Professor, Department of Political Science, Florida State University.

$\ddagger$ Associate Professor, Department of Political Science, Duke University. 
In 2001, Saparmurad Niyazov, who ruled Turkmenistan from 1985 to 2006, announced the publication of his first book. Called Ruhnama (The Book of the Soul), it contained answers to "all of life's questions" and became required reading in all schools, universities, and workplaces. Television news programs were filled with recitations from Niyazov's book, applicants for government jobs were tested on the book during job interviews, and getting a driver's license required taking a sixteen-hour course on the book (Lewis 2008: 81-82; Clark, Golder, and Golder 2013: 362). Niyazov, who called himself Turkmenbashi (Leader of all Turkmen), announced in 2006 that he had interceded with God to ensure that any student who read his book at least three times would automatically get into heaven (Los Angeles Times, 2006). As the undisputed ruler of Turkmenistan, Niyazov spent large sums on megalomaniac construction projects designed to celebrate his rule. For example, the 75-meter high Arch of Neutrality in the capital city of Ashgabad was topped with a 12-meter tall gold-plated statue of Niyazov which rotated throughout the day so that it always faced the sun. Niyazov also changed the names of the months — with January rechristened as the month of Turkmenbashi, April renamed after Niyazov's mother, and September renamed Ruhnama (Lewis 2008: 77-83).

Niyazov's cult of personality occasionally invited parody, as when locals stated tongue-in-cheek that it was actually the sun which revolved around Niyazov's statue (Lewis 2008: 80). Yet compared to many of the other personality cults that arose in the twentieth and twenty-first centuries, the cult surrounding Niyazov was almost subdued. ${ }^{1}$ More extravagant cults of personality include those devoted to Italy's Benito Mussolini (Falasca-Zamponi 1997; Gentile 1996, 2006), Nazi Germany's Adolf Hitler (Vondung 1971; Kershaw 1987, 1998), the Soviet Union's Vladimir Lenin (Tumarkin 1983; Ennker 1997) and Joseph Stalin (Gill 1990; Tucker 1979; Plamper 2012; Davies 1997), and

\footnotetext{
${ }^{1}$ In line with the broader literature we focus our discussion on dictatorships since full-fledged
} cults of personality do not seem to arise in democracies (Plamper 2012: xvii-xviii). This of course does not mean that there cannot be certain discomforting parallels between cults of personality as discussed here and democratic politics. Donald Trump's presidency in particular has invited commentary along these lines. See for example Marquez (2018) and Cohen (2018). 
China's Mao Zedong (Leese 2011; MacFarquhar and Schoenhals 2006). ${ }^{2}$

Personality cults have primarily attracted scholarly attention from social historians who have studied cult practices and products (e.g., Bonnell 1997; Plamper 2012; Falasca-Zamponi 1997). With some notable exceptions (Shih 2008; Márquez 2013; Huang 2015a; Wedeen 1998, 1999; Bush et al. 2016), cults of personality have received little systematic attention in the political science literature. The scholarship that does address these cults offers a range of complementary explanations for their existence that include the psychological needs of dictators, Max Weber's concept of charismatic authority, theories of political religion, authoritarian regimes' propaganda efforts, and strategic interactions either within the ruling elite or between rulers and ruled.

Our paper makes a significant contribution to this last strand of the literature. Building on the notion of preference falsification (Kuran 1991, 1995), we argue that cults provide leaders with important signals about both subordinates' loyalty and what we call disposition-based competence. We formalize this claim to illustrate the consistency of its internal logic and provide support for it with two brief vignettes. Importantly, while prior work assumes that leaders use cults of personality to address a potential moral hazard problem involving their subordinates, we argue that leaders use cults to deal with an adverse selection problem related to subordinate quality when there are multiple, potentially correlated, traits over which the dictator has preferences. In other words, we

${ }^{2}$ Many other communist dictators also established personality cults devoted to their glorification. Examples include Romania's Nicolae and Elena Ceauşescu (Tismaneanu 2003), Albania's Enver Hoxha, and Yugoslavia's Josip Broz Tito. Cults of personality, however, do not only appear in fascist and (post-)communist regimes. Iraq's Saddam Hussein (Makiya 1998: 110-146; Karsh and Rautsi 1991: 120-121, 151-152; Sassoon 2012), Syria's Hafez Al-Assad (Wedeen 1998, 1999), Uganda's Idi Amin, Iran's Ayatollah Khomeini, Zaire's Mobutu Sese Seko, and Libya's Muammar Gaddafi (Post 2015: 25-30) have also had their own cults. Personality cults are also not simply a relic of the past. North Korea's Kim family continues to be the subject of what is probably the most extreme contemporary example of a cult of personality (Myers 2010; Demick 2010: 45-46; Lim 2015). Some observers see personality cults emerging around Russia's Vladimir Putin (Sperling 2016; Motyl 2016) and Turkey's Recep Tayyip Erdoğan (Akyol 2016; Peker and Parkinson 2016). 
view cults of personality as an effective tool for improving subordinate recruitment. The findings from our model run counter to the near consensus in the formal literature that dictators face a loyalty-competence trade-off when hiring and promoting subordinates (Egorov and Sonin 2011; Zakharov 2016). We instead show that, when viewed through the lens of adverse selection, loyal and competent subordinates might act in much the same way. The strategic logic we outline here has important implications for the literature on the internal dynamics of autocracies (e.g., Egorov and Sonin 2011; Svolik 2012; Reuter and Robertson 2012; Wintrobe 1998). Our paper also intersects with the wider literature on propaganda and public opinion formation in authoritarian regimes (e.g., Kern and Hainmueller 2009; Voigtländer and Voth 2014; Huang 2015b) as well as the literature on preference falsification (e.g., Kuran 1991, 1995; Jiang and Yang 2016; Hale and Colton 2017).

In the first section of the paper, we describe the main features of cults of personality. We then survey existing explanations for cults of personality. Next, we informally introduce our model. After that, we present two brief vignettes that illustrate the logic and plausibility of our argument. We subsequently formalize our argument. Finally, we conclude by outlining several implications of our model.

\section{Cults of personality}

We follow Plamper (2004: 33) in defining cults of personality as the "godlike glorification of a modern political leader with mass medial techniques and excessive popular worship for this leader." 3 Cults of personality consist of a set of beliefs, values, myths, symbols, and rituals directed at the adulation of the leader. While the emphasis that particular personality cults put on specific forms of veneration varies, leader worship is typically visible in a number of different domains including mass spectacles and rituals, ostentatious architecture, cult imagery in the visual and performing arts, cult objects, and cult language.

Perhaps the most striking and seemingly irrational aspect of cults of personality is the use

${ }^{3}$ Plamper 2004: 22-33 and Plamper 2012: xiii-xx provide detailed histories of the term "cult of personality." 
of excessive flattery and adulation involving grandiose claims about the infallibility, omniscience, omnipresence, omnipotence, and even divinity of the leader. Such rhetorical extravagance seems to be a common feature of all cults of personality. Mussolini was called a "social archangel," an "envoy of God," and a "man of Providence" (Falasca-Zamponi 1997: 65-66). Hitler was revered as "the greatest German of all times," "the best imaginable expert in every specialized field," and "the highest synthesis of his race" (Waite 1977: 82-83). Stalin was called the "genius of our epoch," the "titan of the world revolution," and the "wise helmsman," among many other epithets (Davies 1997: 150-151). Mao was revered as the "reddest, reddest red sun," "great leader, great teacher, and great helmsman," and "greatest genius of the world" (Leese 2011: 167, 132). Ceauşescu was called the "genius of the Carpathians" (Post 2015: 102) and, together with his wife Elena, "the historic couple whose existence merges with the country's destiny" (Tismaneanu 2003: 219). Hafez al-Assad has been called the "premier pharmacist" who knows "all things about all issues" (Wedeen 1999: 1). While Stalin was in power, all non-fiction writings had to stress his genius. As Service (2005: 545) notes, "History, politics, economics, geography, linguistics and even chemistry, physics and genetics were said to be inadequately studied unless they incorporated his guiding ideas." Similarly, during the Chinese Cultural Revolution, it was claimed that Mao Zedong Thought produced cures for illnesses such as cancer and deafness (Leese 2011: 193). Mussolini was said to be able to stop the flow of lava and make rain fall (Falasca-Zamponetti 1997: 71). Kim Jong-il was credited with the ability to control the weather and teleport from place to place. Even nature supposedly celebrated his birthday with thunder, lightning, and a rainbow during a snowstorm (Hassig and Oh 2009: $33-34)$.

While cults of personality equally fascinate and horrify foreign observers, they can have deadly consequences for both domestic elites and ordinary citizens. As many members of Lenin's Politburo found out, failure to participate in Stalin's cult of personality, or even just being aware of the cult's historical fabrications, could merit a death sentence (Tucker 1990: 303-337). During the Chinese Cultural Revolution, even innocuous mistakes — such as misspelling Mao quotations or inadvertently defacing a newspaper carrying Mao's image - could have lethal consequences (Leese 2011: 206-210; Schoenhals 1992: 19-20). Germans who dared to criticize or joke about Hitler 
risked fatal retribution (Kershaw 1987: 169-225).

\section{Existing explanations for cults of personality}

Perhaps the most common explanation for cults of personality centers on dictators' narcissism and delusions of grandeur. For example, Tucker (1990: 3) concludes that "abundant evidence indicates that Stalin needed a cult as a prop for his psyche as well as for his power." Lewin (1997: 115) states that the Stalin cult was "not just a ruling device" but "generated by the psyche of a man whose vanity was unsatiable [sic]," the outcome of a "deeply seated psychological urge." Fromm (1973: 322) diagnoses Stalin as a mental and physical sadist who wanted to have "absolute and unrestricted control" over human beings and desired to become a god over others. For Kershaw (1998: xxvii), the "one overriding element" in Hitler was his "boundless egomania." The adulation of his followers and his early foreign policy successes convinced Hitler of his own genius — "he became the foremost believer in his own Führer cult" (Kershaw 1998: 591). Glad (2002) argues that Stalin, Hitler, and Saddam Hussein all suffered from malignant narcissism, a diagnosis she offers as an explanation for their thirst for absolute power and their psychological need for obsequious flattery.

Many historical studies of personality cults explicitly draw on Weber's notion of charismatic authority. Weber (1968: 212-245) distinguishes between three ideal types of legitimate domination: rational authority, deriving its legitimacy from universally valid, codified legal norms; traditional or patrimonial authority, which is based on the belief in the sanctity of immemorial traditions; and charismatic authority, based on the exceptional sanctity, heroism, or exemplary character of a single leader. Charismatic authority is "extraordinary" — it emerges in times of social, political, economic, spiritual, or religious crisis (Weber 1968: 241, 1111-1112). For Weber (1968: 1112), charismatic leaders are seen as "the bearers of specific gifts of body and mind" which are considered "supernatural" (in the sense that not everybody can have access to them.) Note that Weber's formulation does not require charismatic leaders to "objectively" have charisma; all that matters is that charismatic leaders are perceived by their followers as charismatic (Weber 1968: 241-242). While not discussed by Weber, who does not directly address the question of why some leaders are perceived as charismatic, it seems plausible that modern mass communications can be employed 
for the creation of such a perception. One example is Hitler's Führer cult, orchestrated by Joseph Goebbels, Reich Minister of Propaganda. Another is the cult of Stalin, who by all accounts had no natural charisma to speak of (Suny 1997: 38) but "masterminded his own cult" (Plamper 2012: 223). Charismatic leaders are not subject to formal appointment or dismissal, supervision or appeal, ordinary jurisdiction, or permanent institutions such as bureaucracies. According to Weber, a charismatic leader "must work miracles, if he wants to be a prophet. He must perform heroic deeds, if he wants to be a warlord. Most of all, his divine mission must prove itself by bringing well-being to his faithful followers; if they do not fare well, he obviously is not the god-sent master" (Weber 1968: 1114). Weber's notion of charismatic authority suggests that cults of personality can be manufactured and genuine at the same time. On the one hand, they are part of the ruling elite's attempt to establish the charismatic authority of the leader. On the other hand, to the extent that the leader has a fellowship that accepts his charismatic authority, cults of personality will also arise naturally due to the emotional bond between charismatic leaders and their true believers. Lepsius (2006) applies Weber's notion of charismatic authority to Hitler; Teiwes (1984) draws on Weber in his discussion of Mao's charismatic authority.

Yet another explanation for the emergence of cults of personality is provided by theories of political religion (Gentile 1996, 2006; Vondung 1971; Mosse 1975; Burrin 1997). For Gentile (2006: xiv), a religion of politics is "a particular form of sacralization of politics that has occurred in the modern era after the political realm had gained its independence from traditional religion." 4 According to Gentile (2006: xiv), "the resulting religion of politics is a religion in the sense that it is a system of beliefs, myths, rituals, and symbols that interpret and define the meaning and end of human existence by subordinating the destiny of individuals and the collectivity to a supreme entity." One view that Gentile (2006: 4-6) calls the crowd manipulation view of political religion is that political leaders engage in the cynical production of political myths and rituals designed to transfigure them into living deities to deceive and control the masses. An opposite view is the fideistic interpretation of political religion, according to which myths and rituals are the

${ }^{4}$ Gentile distinguishes between civil religions and political religions, a difference that maps onto the distinction between democracy and dictatorship. We therefore focus on political religions here. 
"spontaneous expression of the masses, produced by their need for faith and beliefs, which they then satisfy by their devotion to a leader or an ideology that promises them well-being and salvation" (Gentile 2006: 7-8). The emergence of a new political religion is particularly likely "during periods of profound upheaval when long-established faiths are in decline and the hope of a better world becomes more compelling" (Gentile 2006: 8). Mosse (1975), Vondung (1971), and Gentile (2006: 36-38) interpret Nazism as a political religion founded on the deification of the Aryan race, the cult of German blood, anti-semitism, and the idolization of Hitler. Tumarkin (1983) uses the concept of political religion to illuminate the posthumous cult of Lenin, stressing continuities between the Lenin cult and pre-revolutionary Russian religious beliefs. Gentile (1996) interprets fascism and the cult of Mussolini through the lens of political religion.

The traditional political science account of the origins of personality cults is based on Friedrich and Brzezinski's (1966) classic work on totalitarian dictatorship. According to Friedrich and Brzezinski (1966: 19), totalitarian regimes such as Nazi Germany, the Soviet Union, or the People's Republic of China are "a system of rule for realizing totalist intentions under modern political and technical conditions, [...] a novel type of autocracy" (Friedrich and Brzezinski 1966: 17). They argue that such regimes are characterized by six traits, the fourth of which is a "near-complete monopoly of control, in the hands of the party and of the government, of all means of effective mass communication, such as the press, radio, and motion pictures" (Friedrich and Brzezinski 1966: 22). Together with personal agitation efforts and the education system, the regime's control over modern communication technologies allows it to engage in "a nationwide process of brainwashing" for the "achievement of total ideological integration of its people" (Friedrich and Brzezinski 1966: 145). These instruments of "mental molding [...] produce a generation of convinced followers" of the party and its leader (Friedrich and Brzezinski 1966: 145). In this light, cults of personality are a natural outcome of the regime's attempts to "brainwash" the population into supporting the regime..$^{5}$

Recent work in political science offers several additional explanations for cults of personality.

\footnotetext{
${ }^{5}$ For wide-ranging critiques of these and related approaches see Apor et al. 2004 and Leese 2011: $1-24$.
} 
Many of these are based on formal or informal models of strategic interactions either within the ruling elite or between rulers and ruled. Wedeen's $(1998,1999)$ ethnographic study of the cult of Hafez al-Assad seeks to understand why the regime engages in propaganda that not even its creators believe in. In Wedeen's (1999: 6) view, the cult "is a strategy of domination based on compliance rather than legitimacy. The regime produces compliance through enforced participation in rituals of obeisance that are transparently phony both to those who orchestrate them and to those who consume them." Instead of brainwashing Syrians into supporting the regime and its leader, cult imagery and cult discourse clutter public space and displace alternative interpretations of Syrian society and politics. Assad's cult habitualizes citizens to behave as if they believe in the official rhetoric by enforcing guidelines for acceptable speech and behavior, thus turning citizens into accomplices and isolating Syrians from one another.

Huang (2015a) offers an informational argument, using a signaling game to argue that authoritarian propaganda, including that commonly espoused in cults of personality, is often too far-fetched to be believable. The cult's true purpose is therefore not to indoctrinate the population but to signal the regime's power. By spending significant resources on ineffective propaganda activities, dictators can demonstrate their strength to the population, thereby intimidating the masses and preventing popular challenges to their rule.

Shih (2008) argues that subordinates — specifically, Chinese junior officials — can signal loyalty through participation in cults of personality in the form of sycophantic, "nauseating" displays vis-avis a particular senior official. Fawning praise violates a social norm against cults of personality and closes off the possibility of joining another faction, which makes such signals costly and therefore credible. As Shih (2008: 1178) puts it, "by inviting the contempt of others, the sycophants prove their worth by showing that they have no choice but to support their patron." In Shih's (2008) view, cults of personality emerge because junior officials are trying to signal their loyalty while autocrats simultaneously foster norms against sycophancy and cults of personality to preserve the informational value of excessive praise.

Márquez (2013: 3) also focuses on the incentives that subordinates have to ostentatiously venerate their leaders, arguing that "cult practices are first and foremost public signals of support 
for a leader or a regime." In the presence of large-scale patronage relationships, which are common in many authoritarian regimes, "flattery inflation" is likely to emerge as each client attempts to outdo other clients in praising the patron. Cults of personality are therefore the result of inflationary processes that devalue the credibility of previous loyalty signals and lead to the development of extravagant signaling conventions that widen the status gap between leaders and followers.

\section{A new explanation for cults of personality}

Numerous observers have noted that dictators seem to use sycophancy as a test of loyalty, prompting subordinates to engage in excessive flattery to signal their devotion. However, as Shih (2008) has emphasized, excessive flattery does not necessarily constitute a credible signal of loyalty. Both ordinary citizens and regime insiders might overstate their support for the dictator to avoid punishment (Kuran 1991, 1995). Wintrobe (1998: 20-39) calls this phenomenon the Dictator's Dilemma. He observes that "Dictators cannot - either by using force or the threat of force, or by promises even of vast sums of money or chunks of their empires [...] — know whether the population genuinely worships them or worships them because they command such worship." Given the dictator's lack of reliable information about subordinates' loyalty, the decision to promote some of them to positions of power is fraught with peril. If professions of loyalty are merely cheap talk, everyone is going to participate in the cult's glorification of the ruler, robbing the cult of any informational value to the dictator.

Participation in the cult, however, can be a credible signal of loyalty if the sender of the signal incurs some cost. In Shih's (2008) account, a societal norm against cults of personality makes signaling loyalty costly, and therefore credible, in China. While this is an intriguing explanation for how participation in a cult of personality can send a credible signal of loyalty, it may not generalize to other regimes, which typically have social or even legal norms mandating participation in the cult.

Even when loyalty can be credibly signaled, most formal models predict that leaders face a loyalty-competence trade-off when selecting and promoting subordinates. In Egorov and Sonin's (2011) model, for example, dictators may avoid competent subordinates because they are better at sensing when the dictator is vulnerable and are therefore more likely to betray him. Loyalty in 
their model is not an inherent trait, but rather the absence of betrayal. It is thus a retrospective accounting of what the subordinate has done, not a trait correlated with what he will do. Betrayal declines with competence because less competent subordinates have less confidence that the dictator can be deposed, making betrayal riskier and more costly for the dictator's foes to subsidize. In Zakharov's (2016) model, the loyalty-competence trade-off occurs because more competent subordinates have better outside options and thus exert less effort to keep the dictator in power. Loyalty in his model is again not an inherent trait, but rather the level of this regime-maintaining effort the subordinate is willing to perform, whereas competence scales with the marginal cost of providing this effort. Again, loyalty is measured retrospectively, as the amount of effort performed. In both cases competence structures a type of moral hazard problem in which the goal of the dictator is to avoid bad behavior from his subordinates. A lack of bad behavior is interpreted as loyalty.

We diverge in several ways from the extant literature. First, we argue that another, more widely applicable source of signaling costs are the psychological costs of preference falsification. Second, we maintain that these costs are heterogeneous and correlated with personality traits the dictator cares about. Third, we treat loyalty and competence prospectively, as traits valued by a dictator going forward, and thus traits over which the dictator wants to select. Our model thus captures and addresses the dictator's adverse selection problem instead of the moral hazard problem that is at the core of the existing literature.

\subsection{Preference falsification and subordinate competence}

Kuran $(1991,1995)$ introduced the concept of preference falsification into the study of authoritarian regimes. He posits that individuals have two preferences: a private preference and a public preference. The private preference corresponds to the individual's true preference (the preference the individual would express in a completely secret ballot), whereas the public preference is the preference the individual chooses to reveal publicly. Preference falsification denotes the situation in which private and public preferences diverge. Whether an individual engages in preference falsification depends on the trade-off between internal and external payoffs. The external payoff captures the incentives (e.g., promotion) and disincentives (e.g., punishment) for revealing one's 
private preference. The internal payoff is rooted in the psychological costs of preference falsification stemming from loss of personal autonomy and sacrifice of personal integrity. The larger the divergence between an individual's private and public preferences, the larger the psychological costs of "living a lie" (Havel 1985: 20).

The psychological costs of preference falsification are likely to vary across individuals. While some individuals might be comfortable with publicly expressing devotion to a leader they privately despise, others will abhor doing so. Kuran briefly mentions heterogeneity in the tendency to engage in preference falsification but does not incorporate it into his theoretical framework (Kuran 1995: 17, 33-35). Heterogeneity in the psychological costs of preference falsification complicates arguments about the signaling value of participation in personality cults. Subordinates who lavishly praise the dictator might indeed believe the dictator to be a "great helmsman," in which case the discrepancy between their private and public preferences will be small. Alternatively, if subordinates have low psychological costs of preference falsification, they can tolerate a large discrepancy between their private and public preferences, enabling them to engage in excessive flattery purely for opportunistic reasons. It follows that the only subordinates who should fail to engage in excessive flattery are those who do not believe in the leader myth and also have a low psychological tolerance for preference falsification.

This line of reasoning suggests that preference falsification limits but does not fully undermine the informational value of cults of personality to the dictator for two reasons. First, if a subordinate does not participate in the cult, this still provides valuable information to the dictator; he should not promote any subordinates who fail to enthusiastically flatter him. Second, and more importantly, while the cult of personality does not allow the dictator to distinguish between "true believers" and "opportunistic flatterers," loyalty is not the only characteristic of subordinates dictators care about. Dictators also value competence (Egorov and Sonin 2011; Reuter and Robertson 2012; Landry 2008; Wintrobe 1998; Zakharov 2016).

We assume that the psychological costs of preference falsification are negatively correlated with a form of competence we call disposition-based competence. This type of competence is different from the typical concept of competence seen in the authoritarian regimes literature, which we 
call skill-based competence. Disposition-based competence differs from skill-based competence in two important ways. First, disposition-based competence relates to individuals' traits rather than behavior. It captures personality traits such as callousness and unscrupulousness. For example, Gregory (2009: 272) in his study of terror under Stalin writes that "Stalin looked for specific traits in his top security officials: brutality (and even sadism), a clear understanding of his wishes, ruthlessness in carrying out the appointed task." Hayek (1944: 150-151) observed that totalitarian regimes offer "special opportunities for the ruthless and unscrupulous," subordinates who are "completely unprincipled and literally capable of everything." Second, since disposition-based competence captures personality traits and not simply behavior, it is harder to observe than skillbased competence, which makes it more difficult for leaders to screen out potential subordinates who lack this trait.

The psychological literature offers strong evidence for a link between low costs of preference falsification and what we call disposition-based competence. The HEXACO model of personality distinguishes six major dimensions of human personality (Ashton and Lee 2007; Lee and Ashton 2012; Ashton 2018). The Honesty-Humility factor measures individual differences in people's sincerity, fairness, greed avoidance, and modesty. For individuals at the low end of the HonestyHumility scale, flattering, manipulating, and deceiving others is second nature. For such individuals the costs of preference falsification are low.

Low Honesty-Humility is strongly correlated with the "Dark Triad" of Narcissism, Machiavellianism, and psychopathy (Paulhus and Williams 2002; Lee et al. 2013; Ashton 2018: 220). These three personality traits encompass many characteristics that dictators could plausibly value in their subordinates such as a lack of empathy, cynical disregard for morality, callousness, and remorselessness. Low Honesty-Humility is also strongly correlated with Social Dominance Orientation (Pratto et al. 1994; Lee et al. 2010; Altemeyer 1998), which again taps into personality traits potentially useful in dictator's subordinates (such as being dominant, tough, uncaring, power-seeking, and anti-egalitarian within and between groups).

While disposition-based competence might seem most useful in subordinates directly engaged in repression and internal security, we think that dictators will also value it in subordinates serving 
in other roles. In authoritarian regimes, social, cultural, foreign, and economic policies are all geared towards keeping the dictator in power. Achieving this goal will often involve policy choices that benefit the dictator's winning coalition but hurt everyone else (Bueno de Mesquita and Smith 2011). Other things being equal, we would expect subordinates with high levels of disposition-based competence to be more successful in designing and implementing such policies.

Active participation in the cult may thus signal one of three possible sets of characteristics: belief and therefore loyalty (for true believers), disposition-based competence (for opportunistic flatterers), or both. In contrast to earlier formal models (Egorov and Sonin 2011; Zakharov 2016), which generally view one or both of competence or loyalty as choices, we treat both as traits that may be independently valued by the dictator and can be signaled by the subordinate via participation in the dictator's cult of personality. Furthermore, different roles within the dictator's regime may be differently served by subordinates possessing different traits. For example, belief may be most useful for those tasked with propaganda, whereas disposition-based competence may be most valued in roles that involve repression or catering to the regime's winning coalition.

Disposition- and skill-based competence are alike in one important way, however: they both can be dangerous to the leader. Low Honesty-Humility subordinates are likely to develop designs on the leadership role given the chance, and skilled subordinates are likely to be able to follow through on these designs. Dictators have many institutions in place to deal with this, including the use of competing security services, the creation of parallel military organizations, and frequent transfers of key personnel in and out of power and between posts. ${ }^{6}$ Moreover, one of these institutions is the cult of personality itself, which helps dictators slot both types of subordinate into regime roles that make use of their valuable talents while minimizing the danger they pose to the dictator.

Using this setup, we are able to provide a novel argument for the benefits a dictator derives from his cult of personality: it allows him to simultaneously assess two different, valued traits of potential subordinates. As we formally show below, participation in cults of personality turns out to be informative from the dictator's point of view under a wide variety of circumstances, allowing

${ }^{6}$ See, for example, Gregory (2009) for Stalin's tactics, Sassoon (2012) for Saddam Hussein's, and Hassan (2017) for the strategic administration of the internal security apparatus in Kenya. 
him to select subordinates that are both loyal and competent for the most important regime positions. Thus, in our theoretical framework, there need not always be a loyalty-competence trade-off, as predicted by most formal models. Finally, note that like Shih (2008) and Márquez (2013), our analysis of cults of personality focuses on strategic interactions within the ruling elite. Our framework is not intended to explain why the masses participate in cults of personality. ${ }^{7}$

\section{$3.2 \quad$ Illustrative examples}

Before introducing our model, we discuss two brief vignettes to support our interpretation of personality cults. The first example concerns Stalin's rise to power and the second examines an anecdote told by Wedeen $(1998,1999)$ about the cult of Hafez Al-Assad.

\subsubsection{Stalin's cult}

The start of Stalin's cult is often dated to the official celebrations of Stalin's fiftieth birthday in 1929 and the 16th Congress of the Russian Communist Party (Bolsheviks) in 1930, an exercise in devotion to Stalin. ${ }^{8}$ After these events, Stalin took steps to actively further his cult. In order to demonstrate that he was a creative Marxist theoretical mind of the first rank, he assumed the mantle of preeminent living Marxist philosopher by giving speeches implicitly encouraging others to found a "Stalin school" of Soviet philosophy. Tucker (1979: 351) notes that Stalin's speeches were "clearing the way for self-elation by mobilizing the subservient, young, would-be-disciples to dethrone" Marxist philosophers with much greater claims to eminence in Soviet philosophy than Stalin.

The second area selected by Stalin for the propagation of his cult was party history. In a letter

${ }^{7}$ Our approach is related to other work that explains cultural rituals as signaling personality traits for instrumental reasons (e.g., Kuran (1998); Posner (1998); Patel (2012); Schnakenberg (2014)). Our contribution over this previous work is that we show that a dictator might want to create such rituals to solve an adverse selection problem.

${ }^{8}$ The following discussion relies on Tucker (1979). Brandenburger 2011: 51-66 and Service 2004: 357-366, 541-550 provide complementary accounts of the events discussed below. Montefiori (2004) and especially Khlevniuk (2009) discuss interactions within Stalin's inner circle in great detail. 
simultaneously published in October 1931 by two journals, he viciously attacked a previous article by A.G. Slutskii that had cautiously questioned Lenin's position with regards to internal divisions within the pre-1914 German Social Democratic Party. Stalin used his letter for a sweeping attack on "rotten liberalism" and demanded "to put the study of party history onto scientific Bolshevik rails and to sharpen vigilance against Trotskyist and all other falsifiers of the history of our party" (Tucker 1979: 355). Scientific party history, according to Stalin, was less concerned with historical truth and more with demonstrating the higher truths that the party — and its leader, Stalin had declared sacrosanct. To use historical documents in any other way was to slander Bolshevik comrades and to falsify party history. As Tucker convincingly argues, Stalin's letter solicited a Stalin cult in party history. Stalin arrogated to himself the position of leading party historian and asserted the infallibility of Lenin and, by extension, himself as the "firmest and truest pupil" of Lenin (Gill 2011: 116). Following Stalin's letter, Soviet historical scholarship accentuated the importance and merits of Stalin while discrediting those of his enemies. It also erased from the official historical record any facts that no longer seemed befitting for a leader of Stalin's stature.

Stalin's letter had immediate reverberations beyond party history. Many different academic fields including literary criticism, economics, law, engineering, and physics witnessed campaigns by ambitious, unscrupulous academics to reform their own disciplines along Stalinist lines. These "glorifiers" (Tucker 1979: 360) took Stalin's letter as the new gospel, many of them hoping to curry favor by toeing the new party line and contributing to the erection of the Stalin cult. As Tucker (1979: 363) notes, "the one indispensable quality shared by all of the glorifiers, high and low, was pliability. In very many ways the aggrandizement of Stalin required the twisting of truth and the falsification of historical facts."

Tucker's interpretation fits well with our argument. Stalin's call to put party history "onto scientific Bolshevik rails" brought forth an army of opportunistic flatterers willing to distort party history and scholarly knowledge in many other fields in order to impress Stalin with their participation in his cult. Undoubtedly all participants knew that they were engaged in a massive fabrication exercise. True believers might have participated in the belief that Stalin's truth was indeed the higher truth. Opportunistic flatterers on the other hand would have used this opportunity 
to credibly signal their low costs of preference falsification and high level of disposition-based competence, impressing Stalin with their suitability for higher office. The most prominent of them, Lavrentiy Beria, ordered several Georgian historians to produce a new history of the party in Transcaucasia since everything written so far "was defective in its failure to bring out the authentic, real role of Comrade Stalin." Once they were finished he had them shot before publishing their work under his name (Tucker 1990: 333). Beria later became head of the People's Commissariat for Internal Affairs and one of Stalin's chief henchmen (Rayfield 2004). According to Gregory (2009: 44), "Stalin liked Beria because he could be relied upon (like Stalin himself) to kill friend and enemy alike."

\subsubsection{The story of $\mathrm{M}$}

In her work on the cult of Hafez Al-Assad, Wedeen (1998: 503) recounts the following story:

In the spring of 1989 the elite Syrian Presidential Guard discharged officer M after breaking some of his bones. A young officer from a lower middle class 'Alawi family, M had expected his university education to secure him power and privilege within the ranks. He was mistaken. His commanding officer showed no particular respect for M's accomplishments and even prior to the incident that occasioned his beating, his friends often heard him crying in his sleep.

One day a high-ranking officer visiting the regiment ordered the soldiers to recount their dreams of the night before. A soldier stepped forward and announced: "I saw the image of the leader in the sky, and we mounted ladders of fire to kiss it." A second soldier followed suit: "I saw the leader holding the sun in his hands, and he squeezed it, crushing it until it crumbled. Darkness blanketed the face of the earth. And then his face illuminated the sky, spreading light and warmth in all directions." Soldier followed soldier, each extolling the leader's greatness. When M's turn came, he stepped forward, saluted the visiting officer, and said: "I saw that my mother is a prostitute in your

bedroom." The beating and discharge followed. Commenting retrospectively on his 
act, M explained that he had "meant that his country is a whore." 9

Wedeen $(1998,1999)$ uses the story of M as an example of politics "as if:" The soldiers in the story, with the exception of M, all behave as if they believe the cult's claims about Assad's omnipotence. The officer demonstrates that he can elicit such fictions from the soldiers, that he can make them participate in the cult of Assad. The soldiers comply, thereby demonstrating their obedience to the officer and their ability to dissimulate belief in the cult. By complying with the officer's request, each soldier acknowledges the regime's power over him.

Our interpretation of the story of $\mathrm{M}$, and the functions of cults of personality, is somewhat different. In our view, $\mathrm{M}$ is an example of someone for whom the psychological costs of preference falsification are too high to participate in Assad's cult, leading to his beating and dismissal from the army. The other soldiers in his unit succeeded in signaling not just their obedience but their low costs of preference falsification (correlated with disposition-based competence) to the satisfaction of the visiting officer.

\subsection{Cults of personality as signaling mechanisms}

In this section, we formalize the signaling benefit a dictator can receive from his subordinates' participation in his cult of personality. We do this to ensure that signaling over loyalty and disposition-based competence is possible given reasonable assumptions about the preferences of both dictators and their subordinates. Thus, formalizing the argument is a way of checking its internal validity. This is non-trivial: there are conditions under which signaling is more or less easy; probing the internal logic of the argument helps to clarify these. We present the model and describe its results in this section. Proofs for all claims as well as a more complex model in which skill-based disposition may also be signaled are in online appendix A. Online appendix B illustrates the robustness of our claims to variation in some key assumptions.

${ }^{9}$ Wedeen (1998: 504) notes that she does not know whether the events described in the story indeed took place as described to her. We follow her in presuming that "the anecdote typifies an important feature of Syrian political life: the regime's demand that people provide external evidence of their allegiance to a cult whose rituals of obeisance are often transparently phony." 


\subsubsection{Model}

We first present the model and its results in compact form before elaborating below. There are two actors: a dictator (D) and a subordinate $(\mathrm{S})$. The subordinate's type $(\sigma)$ is two dimensional, with dimensions one and two respectively correlated with loyalty and disposition-based competence. Along each dimension the type is dichotomous, so that $\sigma \in\{0,1\}^{2}$. This implies four possible types, which we'll denote for simplicity: 00,01,10,11. Prior beliefs on each type are given by $p_{\sigma}$.

From the perspective of the dictator, each type is best suited to a particular role, respectively denoted $R_{00}, R_{01}, R_{10}, R_{11}$. Each role produces a corresponding reward for the subordinate. We consider all reward orderings consistent with the intent of the model in the appendices; here we assume that $W_{00}<W_{01}<W_{10}<W_{11}$. We start by assuming these are fixed but later consider what changes if they are mutable.

The subordinate may participate in the dictator's cult in order to send a signal of type. This participation signal is denoted $s \in[0, \infty)$. Its cost, $c(s, \sigma)$, is strictly decreasing in both dimensions of the subordinate's type. Though not necessary for our results, for simplicity we assign a constant marginal cost dependent on type, so that $c(s, \sigma)=c_{\sigma} s$. This implies that either: (1) $c_{11}<c_{10}<c_{01}<c_{00}$ or $(2) c_{11}<c_{01}<c_{10}<c_{00}$.

The subordinate's type is private information but the signal is public. The dictator assigns the subordinate to a role after observing the signal. He gets a payoff of 1 if he matches subordinate type to role, and 0 otherwise. The subordinate receives the corresponding reward for the role to which he is assigned regardless of type, minus his type-specific cost for sending the signal.

There are two key equilibrium results of the model. One, the subordinate may perfectly signal his type whenever the orderings of his marginal costs and his rewards are exactly opposed. This happens when the cost ordering (1) is true, given the fixed reward ordering above, and is the best outcome for the dictator.

Two, even when marginal costs are not perfectly aligned with rewards, as in cost ordering (2), the dictator may successfully place subordinates who are either uniformly low or uniformly high on both dimensions in their appropriate roles. The remaining two types are assigned to roles by lottery, minimizing the loss to the dictator even in this case. 
Thus, the dictator is able for the most part to use a cult of personality to successfully staff roles in his regime. Further, if he has the freedom to assign rewards to roles and knowledge of marginal costs, he can align rewards with marginal costs and so assign roles with perfect precision.

We now elaborate on the components of the model and its results.

\subsubsection{Actors and types}

The model just presented in brief focuses on the adverse selection problem we identified above. On one side is a dictator who seeks to match different types of subordinate to the roles in which they would be most useful. On the other side are the dictator's subordinates who seek to get ahead in the regime (or simply avoid abuse) and know they can best accomplish this by signaling significant utility to the dictator. The problem is that subordinates have every incentive to overstate their utility to the dictator. This means that the dictator needs some way of separating out different types of subordinates. We argue that he can do so by parsing their level of participation in his cult of personality. ${ }^{10}$

Above, we discussed three traits possessed by the subordinate ${ }^{11}$ that are of use to the dictator: (1) belief in the dictator, (2) a disposition that enables him to be useful to the dictator, and (3) a set of practical skills that let him succeed in dictator-directed tasks.

We assume that belief is strongly positively correlated with loyalty, in the following sense: the greater one's belief in a dictator's greatness, the less a subordinate should be willing to betray the dictator. While belief might additionally correlate with other traits that are less positive for the dictator, our model assumes that these are captured via disposition or skill. As such, any correlation is an empirical question about the population distribution of types and selecting on belief does not produce unintended negative consequences for the dictator. ${ }^{12}$

\footnotetext{
${ }^{10}$ We assume that the dictator cannot observe the subordinate's type ex post and alter the subordinate's role or benefits accordingly.

${ }^{11}$ We focus on the behavior of a single subordinate, but most of our analysis could extend to a population of subordinates seeking employment.

${ }^{12}$ Relaxing our assumption, we have also analyzed a model in which such negative consequences
} 
Disposition, as we define it, relates to the willingness of a subordinate to "get his hands dirty." As discussed above, we assume that subordinates with lower costs of preference falsification in expectation possess higher levels of this dictator-pleasing disposition. ${ }^{13}$ We view disposition as one element of subordinate competence, in that it affects how well a subordinate might perform his tasks. Another element of competence relates to the skills that the subordinate possesses. More skilled subordinates are naturally better able to satisfy the dictator's demands. To distinguish these two elements of competence we call them disposition-based and skill-based competence.

In the online appendices, we consider a model in which all three traits can be signaled. However, under the reasonable assumptions that there exist separate signals of skill beyond cult participation and that the dictator can construct his cult so that participation in it is not enabled by skill, we show in online appendix A that one can separate signals of skill-based competence from those of belief and disposition-based competence. Thus, to simplify our presentation, here we consider the type of subordinate to be defined in only two dimensions: belief and disposition. We assume values on each dimension are dichotomous. ${ }^{14}$ On the belief dimension we speak of true belief (1) and no

are possible. As might be expected, the dictator does worse, often substantially so, in this circumstance. Yet he can ameliorate this problem if he is able to commit to ordering subordinates' payoffs according to their types rather than their worth to him. In other words, if the dictator can credibly commit to paying true believing subordinates more even though he values them less he can often still achieve positive outcomes. We discuss this in greater detail in online appendix B.

${ }^{13}$ As with belief, a ruthless disposition might end up being a net negative for the dictator, due to the risks such subordinates can pose to the dictator's survival. Certain roles that subordinates may be slotted into may diminish any negative effects of an unscrupulous disposition. Moreover, the model can be adjusted in the manner described in footnote 12 , with the same outcome.

${ }^{14}$ Instead, we could define each of these dimensions continuously with the cost of participating in the dictator's cult (defined below for our model) dependent on these traits. The benefit of this approach would be an increased focus on the microfoundations of our actors' preference orderings. However, as this approach would not alter the central insights of our simpler model we choose not 
belief (0). On the disposition dimension we speak of high disposition-based competence (1) and low disposition-based competence (0).

\subsubsection{Actions and game form}

Our model comprises a two-stage game between the subordinate and the dictator that is preceded by a move by nature. It begins when nature draws a type of subordinate. The dictator knows the distribution from which this type is drawn but not the realization of the type. In the first stage, the subordinate engages in public behavior that is observed by the dictator. This is the participation signal, $s$. In the second stage, the dictator interprets this behavior to draw inferences about the type of subordinate he faces. He then slots the subordinate into a role within the regime. Such roles may be anything from coveted high-level positions (think of Beria) to targets of repression (M in Wedeen's story). Dictators benefit to the degree to which a subordinate's type matches his role. Subordinates benefit from the reward provided to them by the role. Other than our more complex type space, our game form matches that of a standard signaling game (Spence 1973). We utilize a Perfect Bayesian Equilibrium (PBE) solution concept. ${ }^{15}$

To enable signaling, the dictator makes clear (via prior behavior or public pronouncements) which kinds of public behavior will be viewed in which way, providing guidance to the subordinate. ${ }^{16}$ Substantively, this equates to structuring the expectations of the cult. In the language of the model, this is equivalent to engaging in equilibrium selection. We assume the dictator selects the equilibrium that is most informative in making the decision how to slot the subordinate into the regime, as this provides for the best available allocation of personnel and maximizes the dictator's

to pursue it here. We thank [redacted] for this insight.

${ }^{15}$ Spence (1973) considers a second, index dimension of type; however, this dimension is visible to the employer, whereas the dictator cannot observe the subordinate's type along any dimension in our model.

${ }^{16}$ One might model this via an additional screening stage prior to the game; we discuss this in the context of some of our equilibrium findings below. 
utility. $^{17}$

\subsubsection{Utilities}

As noted, the dictator benefits from matching subordinate type to regime role. In contrast, the subordinate gains a type-independent reward from occupying a role that depends only on the nature of the role. This assumption does not require appreciable commitment on the part of a potentially fickle dictator since more valued roles are likely to be intrinsically more rewarding. That being said, below we briefly discuss relaxing this implied ordering over roles in order to consider how the dictator might screen for good subordinates. We note that the only player who suffers from a mismatch between role and type is the dictator. Given complete information over types there would never be a mismatch, but in the presence of incomplete information the dictator may have to assign roles with some probability determined in equilibrium play according to his posterior beliefs over type.

Substantively, this suggests that roles are in a sense uniquely suited to specific types. So, for example, the role $R_{11}$ requires a type high in both loyalty and disposition-based competence. It is not "good enough" to slot a 01 or a 10 type into that role instead: the subordinate would lack the necessary loyalty or disposition, respectively, for the role. Instead, the dictator would prefer a distribution over the 11 type and the 00 type. Although this ensures a positive probability of getting the worst type 00, that type won't fail any more greatly than 01 or 10 would, and this option at least yields the possibility of getting the needed 11 type. ${ }^{18}$ However, this uniqueness

${ }^{17}$ Whenever there are two equally informative equilibria we find both. If belief or disposition is correlated with negative traits, it is possible that the dictator's utility may no longer be maximized at the most informative equilibrium described in footnote 12 . This is because in this case the dictator would have to "overpay" for the services of the subordinate, relative to the subordinate's value, and this overpayment might outweigh the benefit of slotting the subordinate into his optimal role. We discuss this briefly at the end of this section.

${ }^{18}$ One might even argue that types more removed from the ideal would fail less greatly than ones closer, as they would be more likely to make early and egregious errors and thus be more 
assumption is not necessary to induce the dictator to slot subordinates into roles according to posterior beliefs. As long as the benefits from optimal slotting of subordinates into roles sufficiently exceed those for failing to do so, where this metric is defined in relation to the dictator's prior beliefs over subordinate type, our results should go through. ${ }^{19}$

We assume a particular ordering over subordinate rewards, $W$, in which there is no indifference. ${ }^{20}$ In line with our definition of types, roles requiring true believers and more competent subordinates produce the greatest rewards. This still leaves several possible payoff orderings; though we considered only one above, we show in appendix A that our results continue to hold for other orderings.

visible targets of punishment and removal.

${ }^{19}$ One might consider alternative specifications. For instance, a dictator may be strongly risk averse and prefer not to slot any subordinate into an important position if the optimal subordinate cannot be identified with certainty. The general effect of this different assumption on the model would be to reduce the ability of the dictator to solicit information on types via subordinates' behavior since the benefits available in pooling equilibria would decline, sometimes sharply so. Whether a dictator would prefer our risky, more informative equilibria or less risky, less informative equilibria would depend on the dictator's level of risk aversion and strength of priors, among other things. Or, as another example, roles could be fungible and different types could be expected to produce different utility for the dictator. Assuming the dictator were able to commit to a reward schedule, the results of a model with this assumption would be similar to those of our model, save for the interpretation of rewards provided in pooling equilibria. In this model, a set reward would be provided to all types making the same pooling signal, rather than a lottery over roles providing fixed benefits. While this might be a more natural assumption in a firm, we prefer our setup given the poor outside options and decidedly non-market (and often violent) strategies available to dictators to "renegotiate" the terms of any reward schedule.

${ }^{20}$ See footnotes 12 and 13 for a brief discussion of what happens when these assumptions are violated. Also see the discussion in online appendix B. 
In addition to the utility he receives from his role, a subordinate also pays costs based on the signals he sends. Our cost assumptions are also consistent with our definitions of types: while extreme behavior in support of the cult is costly, this cost is lessened for true believers and those who suffer lower costs of preference falsification.

\subsubsection{Results}

As noted above, we assume that the ordering for rewards is: $W_{00}<W_{01}<W_{10}<W_{11}$. This suggests higher rewards for loyalty than disposition-based competence, with the highest rewards for both. However, reversing the two middle payoffs would also be consistent with our assumptions on what the dictator values. As results from this alternative ordering are consistent with the ones we present we relegate this alternative to the appendices. ${ }^{21}$

We do consider here both possible orderings of the subordinate's marginal cost that are consistent with our assumptions on type: (1) $c_{11}<c_{10}<c_{01}<c_{00}$ and $(2) c_{11}<c_{01}<c_{10}<c_{00}$. In ordering (1), true believing but scrupulous types face an easier time of signaling extreme adherence to the cult of personality than non-believing but unscrupulous types, while in (2) the reverse is true.

We consider each of these marginal cost orderings in turn. Under the first ordering, roles with higher rewards are uniformly associated with subordinates who pay lower costs for participating in the cult of personality. As we show in appendix A, this allows a fully separating equilibrium: the 00 type participates the least, followed by the 01, 10, and 11 types, in that order. Each successive type finds it increasingly beneficial to participate, leading to greater equilibrium participation levels that separate it from types that find participation more costly. As a consequence of this separation, the dictator learns the type of the subordinate with perfect precision and is therefore able to place each type into his optimal role. This is the best outcome for the dictator.

When rewards and costs do not align, however, full information revelation is not possible. The dictator's next best solution is one in which the best (11) and worst (00) types are each distinguishable from the rest while the two middle types pool together. In other words, again the 11 type distinguishes himself with the highest signal and the 00 type distinguishes himself with a

\footnotetext{
${ }^{21}$ That is, we only consider appendix A's option A here.
} 
signal of zero, not taking part in the cult. But this time the remaining two types both send the same intermediate signal of cult participation and so cannot be distinguished by the dictator. As a consequence, the dictator responds by slotting all subordinates making this intermediate signal into role $R_{10}$ with probability $\frac{p_{10}}{p_{10}+p_{01}}$ and into role $R_{01}$ with probability $\frac{p_{01}}{p_{10}+p_{01}}$. This is less beneficial for the dictator because he now potentially slots less preferred subordinates into more important roles, and vice versa. However, he still is able to make substantial use of his cult of personality.

Substantively, costs are more likely to be misaligned with rewards, given our ordering, when important positions require extreme loyalty but such loyalty is easy to fake. This might occur, for example, in the context of a dictator who is worried about the possibility of a coup. As Wintrobe (1998: 39) argues and Svolik (2012: 3-8) shows empirically, dictators often have good reasons to be paranoid.

Despite the imperfect nature of signaling in the context of misaligned costs, however, our results paint a clear picture of the role of a personality cult in providing information to the dictator. Dictators are able to develop and use a cult of personality to great effect, learning the types of subordinates and using this information to better slot them into appropriate roles in the regime. This conclusion is largely robust to relaxing our key modeling assumptions, as discussed in online appendix B.

Further, the flaws in the system that prevent the dictator from using his cult of personality to perfectly solve his adverse selection problem and thus entirely avoid the loyalty-competence trade-off rely on constraints on his ability to credibly commit to rewards that match the ordering of his subordinates' marginal costs. A simple extension of our model adds a screening stage. Here the dictator would construct the cult itself, which amounts to making known what level of participation would be rewarded by what role. In other words, in the screening stage he would set the ordering of rewards. As we discuss at more length in appendix B, there are conditions under which the dictator's ability to do so will be constrained. For example, the dictator may not be able to credibly commit to a schedule of rewards, or he may not desire to make such a commitment due to its cost. The latter is more likely when the ordering of rewards diverges from our assumptions. When constrained, our analysis indicates that the dictator may not be able to perfectly solve his adverse 
selection problem, though he can still do pretty well. However, when such constraints do not bind, the dictator should be able to construct his cult of personality in such as way so as to secure a perfect solution to his adverse selection problem. In such a circumstance, the cult of personality is a rational mechanism for securing optimal use of subordinates both competent and loyal.

\section{Conclusion}

We have offered a novel rational explanation for why cults of personality exist: they solve the dictator's adverse selection problem in assigning subordinates to roles within the regime. Of course, our explanation is designed to complement, not replace, alternative explanations of cults of personality. Presumably, many different factors contribute to the emergence of a cult of personality, with the weight of a given factor varying across cases. Here, we highlight one factor that so far has not been mentioned in the literature: participation in a cult of personality not only provides information about loyalty but also signals personality traits that can be beneficial to a dictator. Our analytical framework, which focuses on the dictator's need to recruit loyal and competent subordinates, thus complements existing rational explanations for cults of personality that similarly focus on the interactions between dictator and subordinates (e.g., Shih 2008; Márquez 2013). Our explanation started with the observation that participation in a cult of personality is psychologically costly when it requires subordinates to engage in preference falsification. These costs of preference falsification are likely to vary across individuals. What matters from the dictator's perspective is that low psychological costs of preference falsification are correlated with traits the dictator values, such as unscrupulousness and ruthlessness, which we collectively term disposition-based competence. Under a wide variety of circumstances, this in turn makes participation in cults of personality informative from the dictator's point of view, allowing him to select subordinates that are both loyal and competent for the most important regime positions. In contrast to earlier formal work, our model implies that dictators do not necessarily face a loyalty-competence trade-off in selecting and promoting subordinates. In fact, dictators can use cults of personality to avoid this trade-off. Our results thus imply that despite the apparent absurdity of cults of personality, dictators have strong incentives to establish a cult of personality devoted to their glorification apart from any pleasure they might derive from their veneration or the cult's propaganda value. 
Indeed, cults of personality are a valuable tool in a dictator's toolkit precisely because of their phony and absurd nature. 


\section{$5 \quad$ References}

Altemeyer, Bob. 1998. "The other 'authoritarian personality'." In Mark P. Zanna (ed.). Advances in experimental social psychology 30, 47-92.

Ashton, Michael C. 2018. Individual differences and personality. Third edition. Academic Press.

Ashton, Michael C. and Kibeom Lee. 2007. "Empirical, theoretical, and practical advantages of the HEXACO model of personality structure." Personality and Social Psychology Review $11(2):$ 150-166.

Akyol, Mustaga. June 21, 2016. “Erdoganism [noun]: From 'national will' to 'man of the nation,' an abridged dictionary for the post-secular Turkish state." Foreign Policy. https://goo.gl/tOHvGp. Retrieved August 23, 2016.

Apor, Balázs, Jan C. Behrends, Polly Jones, and E. A. Rees. 2004. The leader cult in communist dictatorships: Stalin and the Eastern bloc. Palgrave Macmillan.

Brandenburger, David. 2011. Propaganda state in crisis: Soviet ideology, indoctrination, and terror under Stalin, 1927-1941. Yale University Press.

Bueno de Mesquita, Bruce and Alastair Smith. 2011. The dictator's handbook. PublicAffairs. Burrin, Philippe. 1997. "Political religion: The relevance of a concept." History and Memory $9(1 / 2): 321-349$.

Bush, Sarah Sunn, Aaron Erlich, Lauren Prather, and Yael Zeira. 2016. "The effects of authoritarian iconography: An experimental test." Comparative Political Studies 49 (13): $1704-1738$.

Clark, William Roberts, Matt Golder, and Sona Nadenichek Golder. 2013. Principles of comparative politics. Second edition. CQ Press.

Cohen, Eliot A. 2018. "Team of sycophants." The Atlantic, March 14.

Davies, Sarah. 1997. Popular opinion in Stalin's Russia. Cambridge University Press. 
Demick, Barbara. 2010. Nothing to envy: Ordinary lives in North Korea. Spiegel \& Grau. Egorov, Georgy and Konstantin Sonin. 2011. "Dictators and their viziers: Endogenizing the loyalty-competence trade-off." Journal of the European Economic Association 9 (5): 903-930.

Ennker, Benno. 1997. Die Anfänge des Leninkults in der Sowjetunion. Böhlau Verlag. Falasca-Zamponi, Simonetta. 1997. Fascist spectacle: The aesthetics of power in Mussolini's Italy. University of California Press.

Friedrich, Carl J. and Zbigniew K. Brzezinski. 1966. Totalitarian dictatorship and autocracy. Second edition. New York: Praeger.

Fromm, Erich. 1973. The anatomy of human destructiveness. New York: Henry Holt.

Gentile, Emilio. 1996. The sacralization of politics in Fascist Italy. Harvard University Press. Gentile, Emilio. 2006. Politics as religion. Princeton University Press.

Gill, Graeme. 1990. The origins of the Stalinist political system. Cambridge University Press. Gill, Graeme. 2011. Symbols and legitimacy in Soviet politics. Cambridge University Press. Glad, Betty. 2002. "Why tyrants go too far: Malignant narcissism and absolute power." Political Psychology 23 (1): 1-37.

Gregory, Paul R. 2009. Terror by quota. Yale University Press.

Hale, Henry E. and Timothy J. Colton. 2017. "Who defects? Unpacking a defection cascade from Russia's dominant party 2008-12." American Political Science Review 111 (2): 322-337. Hassan, Mai. 2017. "The strategic shuffle: Ethnic geography, the internal security apparatus, and elections in Kenya." American Journal of Political Science 61 (2): 382-395.

Hassig, Ralph and Kongdan Oh. 2009. The hidden people of North Korea: Everyday life in the Hermit Kingdom. Rowman \& Littlefield.

Havel, Václav. 1985. The power of the powerless: Citizens against the state in central-eastern Europe. Routledge. 
Hayek, Friedrich A. 1944. The road to serfdom. University of Chicago Press.

Huang, Haifeng. 2015a. "Propaganda as signaling." Comparative Politics 47 (4): 419-444.

Huang, Haifeng. 2015b. "International knowledge and domestic evaluations in a changing society: The case of China." American Political Science Review 109 (3): 613-634.

Jiang, Junyan and Dali L. Yang. 2016. "Lying or believing? Measuring preference falsification from a political purge in China." Comparative Political Studies 49 (5): 600-634.

Karsh, Efraim and Inari Rautsi. 1991. Saddam Hussein: A political biography. Grove Press. Kern, Holger L. and Jens Hainmueller. 2009. "Opium for the masses: How foreign media can stabilize authoritarian regimes." Political Analysis 17 (4): 377-399.

Kershaw, Ian. 1987. The 'Hitler myth': Image and reality in the Third Reich. Clarendon Press.

Kershaw, Ian. 1998. Hitler. 1889-1936: Hubris. W.W. Norton \& Co.

Khlevniuk, Oleg V. 2009. Master of the house: Stalin and his inner circle. Yale University Press.

Kuran, Timur. 1991. "Now out of never: The element of surprise in the East European revolution of 1989." World Politics 44 (1): 7-48.

Kuran, Timur. 1995. Private truths, public lies: The social consequences of preference falsification. Harvard University Press.

Kuran, Timur. 1998. "Ethnic norms and their transformation through reputational cascades." Journal of Legal Studies 27 (S2): 623-659.

Landry, Pierre. 2008. Decentralized authoritarianism in China: The Communist Party's control of local elites in the post-Mao era. Cambridge University Press.

Lee, Kibeom and Michael C. Ashton. 2012. The H factor of personality. Wilfred Laurier University Press.

Lee, Kibeom, Michael C. Ashton, Babatunde Ogunfowora, Joshua S. Bourdage, and Kang- 
Hyun Shin. 2010. "The personality bases of socio-political attitudes: The role of HonestyHumility and Openness to Experience." Journal of Research in Personality 44 (1): 115-119. Lee, Kibeom, Michael C. Ashton, Jocelyn Wiltshire, Joshua S. Bourdage, Beth A. Visser, and Alissa Gallucci. 2013. "Sex, power, and money: Prediction from the Dark Triad and Honesty-Humility." European Journal of Personality 27 (2): 169-184.

Leese, Daniel. 2011. Mao cult: Rhetoric and ritual in China's cultural revolution. Cambridge University Press.

Lepsius, M. Rainer. 2006. "The model of charismatic leadership and its applicability to the rule of Adolf Hitler." Totalitarian movements and political religions 7 (2): 175-190.

Lewis, David. 2008. The temptations of tyranny in Central Asia. Hurst \& Company.

Lewin, Moshe. 1997. "Stalin in the mirror of the other." In Ian Kershaw and Moshe Lewin (eds.). Stalinism and nazism: Dictatorships in comparison. Cambridge University Press.

Lim, Jae-Cheon. 2015. Leader symbols and personality cult in North Korea: The leader state. Routledge.

Los Angeles Times. March 21, 2006. "Read my words, go to heaven, leader says." Los Angeles Times. https://goo.gl/QX5Bq1. Retrieved August 23, 2016.

Márquez, Xavier. 2013. "A model of cults of personality." Working paper.

Marquez, Xavier. 2018. "Why Trump administration officials try so hard to flatter him." Monkey Cage, January 10.

MacFarquhar, Roderick and Michael Schoenhals. 2006. Mao's last revolution. Belknap Press. Makiya, Kanan. 1998. Republic of fear: The politics of modern Iraq. Updated edition. University of California Press.

Montefiore, Simon Sebag. 2004. Stalin: The court of the Red Tsar. Alfred A. Knopf. Mosse, George L. 1975. The nationalization of the masses: Political symbolism and mass movements in Germany from the Napoleonic wars through the Third Reich. Howard Fertig. 
Motyl, Alexander J. 2016. "Putin's Russia as a fascist political system." Communist and Post-Communist Studies 49 (1): 25-36.

Myers, B. R. 2010. The cleanest race: How North Koreans see themselves - and why it matters. Melville House.

Patel, David S. 2012. "Concealing to reveal: The informational role of Islamic dress." Rationality and Society 24 (3): 295-323.

Paulhus, Delroy L. and Kevin M. Williams. 2002. "The Dark Triad of personality: Narcissism, Machiavellianism, and psychopathy." Journal of Research in Personality 36 (6): 556-563.

Peker, Emre, and Joe Parkinson. 2016. "Turkey's Erdogan is turning into a strongman." https://goo.gl/A61Itb. Wall Street Journal, December 25, 2016.

Plamper, Jan. 2012. The Stalin cult: A study in the alchemy of power. Yale University Press. Posner, Eric A. 1998. "Symbols, signals, and social norms in politics and the law." Journal of Legal Studies 27 (S2): 765-797.

Post, Jerrold M. 2015. Narcissism and politics: Dreams of glory. Cambridge University Press.

Pratto, Felicia, Jim Sidanius, Lisa M. Stallworth, and Bertram F. Malle. 1994. "Social Dominance Orientation: A personality variable predicting social and political attitudes." Journal of Personality and Social Psychology 67 (4): 741-763.

Rayfield, Donald. 2004. Stalin and his hangmen: The tyrant and those who killed for him. Random House.

Reuter, Ora John and Graeme B. Robertson. 2012. "Subnational appointments in authoritarian regimes: Evidence from Russian gubernatorial appointments." Journal of Politics 74 (4): 1023-1037.

Sassoon, Joseph. 2012. Saddam Hussein's Ba'th Party: Inside an authoritarian regime. Cambridge University Press.

Schnakenberg, Keith E. 2014. "Group identity and symbolic political behavior." Quarterly 
Journal of Political Science 9: 137-167.

Schoenhals, Michael. 1992. Doing things with words in Chinese politics: Five studies. Institute of East Asian Studies, University of California.

Service, Robert. 2005. Stalin: A biography. Belknap Press.

Shih, Victor Chung-Hon. 2008. "NNauseating' displays of loyalty: Monitoring the factional bargain through ideological campaigns in China." Journal of Politics 70 (4): 1177-1192.

Spence, Michael. 1973. "Job market signaling." Quarterly Journal of Economics 87 (3): $355-374$.

Sperling, Valerie. 2016. "Putin's macho personality cult." Communist and Post-Communist Studies 49 (1): 13-23.

Suny, Ronald Grigor. 1997. "Stalin and his stalinism: Power and authority in the Soviet Union, 1930-1953." In Ian Kershaw and Moshe Lewin (eds.). Stalinism and nazism: Dictatorships in comparison. Cambridge University Press.

Svolik, Milan W. 2012. The politics of authoritarian rule. Cambridge University Press.

Teiwes, Frederick C. 1984. Leadership, legitimacy, and conflict in China. M.E. Sharpe.

Tismaneanu, Vladimir. 2003. Stalinism for all seasons: A political history of Romanian communism. University of California Press.

Tucker, Robert C. 1979. "The rise of Stalin's personality cult." American Historical Review $84(2): 347-366$.

Tucker, Robert C. 1990. Stalin in power: The revolution from above 1928-1941. W.W. Norton \& Co.

Tumarkin, Nina. 1983. Lenin lives! The Lenin cult in Soviet Russia. Harvard University Press.

Voigtländer, Nico and Hans-Joachim Voth. 2014. "Nazi indoctrination and anti-Semitic beliefs in Germany." Proceedings of the National Academy of Science 112 (26): 7931-7936. 
Vondung, Klaus. 1971. Magie und Manipulation: Ideologischer Kult und politische Religion des Nationalsozialismus. Vandenhoeck \& Ruprecht.

Waite, Robert G. L. 1977. The psychopathic god: Adolf Hitler. Basic books.

Weber, Max. 1968. Economy and society: An outline of interpretive sociology. Edited by Guenther Roth and Claus Wittich. Bedminster Press.

Wedeen, Lisa. 1998. "Acting 'as if': Symbolic politics and social control in Syria." Comparative Studies in Society and History 40 (3): 503-523.

Wedeen, Lisa. 1999. Ambiguities of domination: Politics, rhetoric, and symbols in contemporary Syria. University of Chicago Press.

Wintrobe, Ronald. 1998. The political economy of dictatorship. Cambridge University Press. Zakharov, Alexei V. 2016. "The loyalty-competence trade-off in dictatorships and outside options for subordinates." Journal of Politics 78 (2): 457-466. 


\section{Online appendix A: Proofs for the formal model}

In this appendix, we present the proofs for an extension of the formal model in the text in which we consider skill-based competence in addition to loyalty and disposition-based competence. Our results in the text follow from the simplified version of the model presented below. Throughout, we assume that indifferent subordinates always choose the smaller signal, to represent the inherent uncertainty in expected rewards provided by a role within a dictator's regime.

We begin by briefly introducing the extended model that incorporates skill-based competence, before solving for its equilibria. The dictator maintains the same preferences and actions as in the text, save that he also has optimal roles for skilled and unskilled subordinates in his regime, with the former receiving higher rewards than the latter, all else equal.

The subordinate has three traits of use to the dictator: belief, which is correlated with loyalty; disposition; and skills. We assume values are dichotomous on each dimension, with true- $(T)$ and non- $(N)$ believing subordinates, high- $(H)$ and low- $(L)$ disposition subordinates, and skilled $(S)$ and unskilled $(U)$ subordinates. Note that we have shifted to these letters from the 1 and 0 we used in the text to avoid confusion over ordering of traits in subscripts. But $T$ and $H$ are the 1 types and $N$ and $L$ are the 0 types from the text. We refer to the extended type of subordinate as $\phi \in\{T H S, T H U, T L S, T L U, N H S, N H U, N L S, N L U\}$, with priors over type equal to $p_{\phi}$.

The main complexity of this extended model lies in the inference step. The public behavior of the subordinate may be complex, so that drawing conclusions from it is not straightforward for the dictator. In line with our discussion in the text, we assume that the dictator can draw two independent signals from the subordinate's public behavior. One signal, $s^{1} \in[0, \infty]$, captures observable implications of public behavior that inform the dictator's inference with respect to the subordinate's skill-based competence. Measures of performance on tasks that require skill and not merely disposition or loyalty would fall into this category. The other signal, $s^{2} \in[0, \infty]$, captures the extremity of the subordinate's public behavior with respect to the expectations associated with adherence to the dictator's cult of personality. This $s^{2}$ is the participation signal $s$ in the text.

Given the dictator's preference to slot subordinates into their optimal roles, the dictator benefits if successful adherence to extreme cult behavior does not rely on the skill level of the subordinate. If this were not true, it would be more difficult for the dictator to separate out subordinates' differences in skill from differences in belief or disposition. The reason is that in this case true believers and those with high disposition-based competence could use these traits to achieve similar levels of extremism as the highly-skilled. We assume that dictators are aware of this in designing their cults. Thus, adherence to expected cult behavior does not provide information as to skill within our model. ${ }^{1}$

The dictator would, of course, also like to separate out disposition from belief. However, there is no simple way to observe behavior that can distinguish the flattery of the unscrupulous from the true beliefs of the fanatic. Thus, the subordinate's public behavior only produces two signals.

Each signal has a cost associated with it. One cost relates to the signal of skill, $s^{1}$. The greater this signal of effort and competence, the higher the cost, though the marginal rate of increase in cost with signal is less for the skilled types than for the unskilled types. Substantively, the dictator can observe outcomes, such as local economic performance or managerial efficiency, that are increasing in subordinate skill. A second cost is proportional to the extremity of behavior within

${ }^{1}$ Given that we assume that the dictator designed the cult for his benefit, and given that it benefits him to have skill-based competence be distinguishable, it is safe to assume that his cult would divorce skill from cult behavior. 
the dictator's cult of personality. As discussed in the text, we assume that more extreme behavior (greater $s^{2}$ ) entails higher costs than less extreme behavior, all else equal, and that marginal costs are higher for low-disposition types and non-believers.

Together, this suggests a cost structure $c\left(s^{1}, s^{2}, \phi\right)$ that is separable in skill. Define $\sigma \in$ $\{T H, T L, N H, N L\}$ as the reduced type (i.e., the type absent the skill dimension, which is what we use in the text), and let $i \in\{S, U\}$ refer to skill alone. We set the cost as $c_{i}^{1} s^{1}+c_{\sigma}^{2} s^{2}$. This implies the following utility for the subordinate: $u\left(s^{1}, s^{2}, \phi\right)=W\left(s^{1}, s^{2}\right)-c\left(s^{1}, s^{2}, \phi\right)$, where $W\left(s^{1}, s^{2}\right)$ is the expected reward for the subordinate resulting from the equilibrium distribution over roles he faces given signals $s^{1}, s^{2}$. Our assumptions on $c_{\sigma}^{2}$ specify which types face higher and lower costs, but not the full ordering. We account for this in the analysis below.

We begin this analysis by first separating out signaling over skill-based disposition. Assume that there exists an equilibrium of the game absent consideration of skills, and that the equilibrium payoff to type $\sigma$ is $W^{\sigma}$, where $\sigma \in\{T H, T L, N H, N L\}$ is the reduced type. Also define two-dimensional versions of $W^{\sigma}$ and $c\left(s^{2}, \sigma\right)=c_{\sigma}^{2} s^{2}$ in the natural way. In other words, ignoring the type and signal of skill leaves one with four types of subordinate who attempt to distinguish themselves via a signal $s^{2}$. We will show later that an equilibrium to this game always exists, satisfying our assumption.

Now reintroduce skill. Because dictators value skilled subordinates more, all else equal, we know that $W_{S}^{\sigma} \geq W_{U}^{\sigma}$ for all $W^{\sigma}$, where $W_{S}^{\sigma}$ and $W_{U}^{\sigma}$ are the expected payoffs skilled and unskilled subordinates of reduced type $\sigma$ respectively receive in this equilibrium. These expected payoffs are constructed in the usual manner: e.g., $W_{S}^{T H}=W_{T H S}$ if $W^{T H}=W_{T H}$, whereas $W_{S}^{T H}=q W_{T H S}+(1-q) W_{T L S}$ if $W^{T H}=q W_{T H}+(1-q) W_{T L}$. In other words, translate the expected payoff from the equilibrium of the simplified game without skill into the expected payoff from the equilibrium with skill by simply adding skill.

For any $s^{2}$ we have that $c\left(s^{1}, s^{2}, S\right)<c\left(s^{1}, s^{2}, U\right)$ for all $s^{1}>0$. The most informative PBE relating to the signal $s^{1}$ sets a different, and higher, signal for the skilled type than the unskilled type. The signal of the latter must be zero, given this, as it is costly. Define $\hat{s}^{1}$ as the equilibrium signal of the skilled type, so that this signal is perfectly informative, as long as off-the-path beliefs are such that signals below $\hat{s}^{1}$ are assumed to arise from unskilled agents only, which we assume. To see this is a valid separating PBE, note that: (i) the dictator will slot all those playing $\hat{s}^{1}$ into the higher payoff role given his beliefs; (ii) the skilled $\sigma$ type will not want to deviate to zero as long as $W_{S}^{\sigma}-W_{U}^{\sigma} \geq c_{S}^{1} \hat{s}^{1}$; and (iii) the unskilled $\sigma$ type will not want to deviate to $\hat{s}^{1}$ as long as $W_{S}^{\sigma}-W_{U}^{\sigma} \leq c_{U}^{1} \hat{s^{1}}$. As $c_{S}^{1}>c_{U}^{1}$, such an $\hat{s}^{1}$ always exists; its most efficient value is $\frac{W_{S}^{\sigma}-W_{U}^{\sigma}}{c_{U}^{1}}$.

Thus, we can treat the dictator's adverse selection problem in two steps. First, the dictator forms beliefs about the reduced type of subordinate via the signal $s^{2}$. Second, the dictator discerns via the signal $s^{1}$ if the subordinate is skilled or unskilled. Together, this allows him to slot the subordinate into the appropriate role.

Given this, to simplify our notation in the rest of the appendix, we will drop references to the skill-based competence trait and use only reduced type. The preceding analysis indicates how to extend this to include the skill dimension. In addition to the restrictions to reduced type on $W$ and $c^{2}$, we define reduced type priors as $p_{T H}, p_{N H}, p_{T L}, p_{N L}$.

The text offers two different orderings for the $c_{\sigma}^{2}$ parameters that are consistent with our theory. Though there are also only two orderings for the reward parameters $W_{\sigma}$ that are consistent, we consider an additional three options for reward orderings. We do this in order to facilitate discussion of robustness, which we take up in online appendix B. ${ }^{2}$ We compute the most informative PBE for

\footnotetext{
${ }^{2}$ These options cover only those discussed in the text or online appendix B; they are not a full
} 
each, showing that no more informative equilibrium is possible in each case. The options are

- $(\mathrm{X} 1) W_{T H}=W_{N H}>W_{T L}=W_{N L}, c_{T H}^{2}<c_{T L}^{2}<c_{N H}^{2}<c_{N L}^{2}$,

- $(\mathrm{X} 2) W_{T H}=W_{N H}>W_{T L}=W_{N L}, c_{T H}^{2}<c_{N H}^{2}<c_{T L}^{2}<c_{N L}^{2}$,

- $(\mathrm{A} 1) W_{T H}>W_{T L}>W_{N H}>W_{N L}, c_{T H}^{2}<c_{T L}^{2}<c_{N H}^{2}<c_{N L}^{2}$,

- (A2) $W_{T H}>W_{T L}>W_{N H}>W_{N L}, c_{T H}^{2}<c_{N H}^{2}<c_{T L}^{2}<c_{N L}^{2}$,

- (B1) $W_{T H}>W_{N H}>W_{T L}>W_{N L}, c_{T H}^{2}<c_{T L}^{2}<c_{N H}^{2}<c_{N L}^{2}$,

- $(\mathrm{B} 2) W_{T H}>W_{N H}>W_{T L}>W_{N L}, c_{T H}^{2}<c_{N H}^{2}<c_{T L}^{2}<c_{N L}^{2}$,

- $(\mathrm{Ci} 1) W_{N H}>W_{T H}>W_{N L}>W_{T L}, c_{T H}^{2}<c_{T L}^{2}<c_{N H}^{2}<c_{N L}^{2}$,

- $(\mathrm{Ci} 2) W_{N H}>W_{T H}>W_{N L}>W_{T L}, c_{T H}^{2}<c_{N H}^{2}<c_{T L}^{2}<c_{N L}^{2}$,

- (Cii1) $W_{N H}>W_{N L}>W_{T H}>W_{T L}, c_{T H}^{2}<c_{T L}^{2}<c_{N H}^{2}<c_{N L}^{2}$,

- $(\mathrm{Cii2}) W_{N H}>W_{N L}>W_{T H}>W_{T L}, c_{T H}^{2}<c_{N H}^{2}<c_{T L}^{2}<c_{N L}^{2}$.

Our proof strategy for each option is as follows. First we propose a fully separating equilibrium, with equilibrium signals $s_{T H}^{2}, s_{N H}^{2}, s_{T L}^{2}$, and $s_{N L}^{2}$. In such an equilibrium, posterior beliefs are simple: the dictator knows the type of subordinate with certainty in equilibrium. We enable this with the following off-the-path beliefs: should the subordinate make a signal that is not one of the defined equilibrium signals, then the dictator believes that the subordinate is the type corresponding to the next lowest equilibrium signal, or the least preferred type if there are no lower equilibrium signals. ${ }^{3}$ As the dictator's equilibrium decision to slot subordinates into roles according to the dictator's posterior beliefs about the subordinate's type is induced by the dictator's preferences, and as the benefits the dictator provides are fixed by role, and are not decision variables, all we need to do to check if such an equilibrium exists is to check the incentive compatibility constraints for each type of subordinate. No type of subordinate must want to deviate from the proposed equilibrium for us to have a fully-informative equilibrium. If one or more types do want to deviate then we instead fashion the next-most informative equilibrium. In doing so we restrict ourselves to pure strategies. We start by providing the general incentive compatibility constraints and then specialize to each option.

ordering.

${ }^{3}$ In other words, the dictator splits the signal space into convex regions, and all signals within each region signal a particular type. 
The general incentive compatibility constraints, ignoring indifference, are:

$$
\begin{array}{rlr}
W_{T H}-c_{T H}^{2} s_{T H}^{2} & \geq & W_{T L}-c_{T H}^{2} s_{T L}^{2}, \\
& \geq & W_{N H}-c_{T H}^{2} s_{N H}^{2}, \\
\geq & W_{N L}-c_{T H}^{2} s_{N L}^{2}, \\
W_{T L}-c_{T L}^{2} s_{T L}^{2} & \geq & W_{T H}-c_{T L}^{2} s_{T H}^{2}, \\
& \geq & W_{N H}-c_{T L}^{2} s_{N H}^{2}, \\
\geq & W_{N L}-c_{T L}^{2} s_{N L}^{2}, \\
W_{N H}-c_{N H}^{2} s_{N H}^{2} \geq & W_{T H}-c_{N H}^{2} s_{T H}^{2}, \\
\geq & W_{T L}-c_{N H}^{2} s_{T L}^{2}, \\
W_{N L}-c_{N L}^{2} s_{N L}^{2} & \geq & W_{N L}-c_{N H}^{2} s_{N L}^{2}, \\
\geq & W_{T H}-c_{N L}^{2} s_{T H}^{2}, \\
\geq & W_{T L}-c_{N L}^{2} s_{T L}^{2}, \\
& W_{N H}-c_{N L}^{2} s_{N H}^{2} .
\end{array}
$$

These twelve inequalities comprise pairs of expressions that specify the bounds for each difference between equilibrium signals. Consequently, we can rewrite these twelve as six inequalities that will prove useful. These are:

$$
\begin{array}{lll}
\frac{W_{T H}-W_{N L}}{c_{N L}^{2}} \leq & s_{T H}^{2}-s_{N L}^{2} \leq & \frac{W_{T H}-W_{N L}}{c_{T H}^{2}}, \\
\frac{W_{T L}-W_{N L}}{c_{N L}^{2}} \leq & s_{T L}^{2}-s_{N L}^{2} \leq & \frac{W_{T L}-W_{N L}}{c_{T L}^{2}}, \\
\frac{W_{N H}-W_{N L}}{c_{N L}^{2}} \leq & s_{N H}^{2}-s_{N L}^{2} \leq & \frac{W_{N H}-W_{N L}}{c_{N H}^{2}}, \\
\frac{W_{T H}-W_{T L}}{c_{T L}^{2}} \leq & s_{T H}^{2}-s_{T L}^{2} \leq & \frac{W_{T H}-W_{T L}}{c_{T H}^{2}}, \\
\frac{W_{T H}-W_{N H}}{c_{N H}^{2}} \leq & s_{T H}^{2}-s_{N H}^{2} \leq & \frac{W_{T H}-W_{N H}}{c_{T H}^{2}}, \\
\frac{W_{T L}-W_{N H}}{c_{N H}^{2}} \leq & s_{T L}^{2}-s_{N H}^{2} \leq & \frac{W_{T L}-W_{N H}}{c_{T L}^{2}} .
\end{array}
$$

\section{Option X}

In option $\mathrm{X}, W_{T H}=W_{N H}>W_{T L}=W_{N L}$. The left-hand side (LHS) of this expression and (5) imply that $s_{T H}^{2}=s_{N H}^{2}$. The right-hand side (RHS) of this expression and (2) imply that $s_{T L}^{2}=s_{N L}^{2}$. Thus we cannot have a fully-separating equilibrium under option X.

However, since high disposition is rewarded more than low disposition in this option, regardless of subordinate belief, we can try to set up a semi-separating equilibrium that groups together all high disposition types. Relative to the dictator's preferences under this option, this semi-separating equilibrium would be just as beneficial as a fully-separating one, since it would allow the dictator to slot all types of subordinate the dictator differentiates into appropriate roles. We thus posit a PBE in which both $T H$ and $N H$ types pool on signal $\hat{s^{2}}=\frac{W^{H}-W^{L}}{c_{T L}^{2}}$ and the other two types 
pool on signal 0. Let $W^{H}=\frac{p_{T H} W_{T H}}{p_{T H}+p_{N H}}+\frac{p_{N H} W_{N H}}{p_{T H}+p_{N H}}$ and $W^{L}=\frac{p_{T L} W_{T L}}{p_{T L}+p_{N L}}+\frac{p_{N L} W_{N L}}{p_{T L}+p_{N L}} \cdot{ }^{4}$ By assumption, $W^{H}>W^{L}$.

Inequalities (1)-(6) then reduce to the following four inequalities:

$$
\begin{array}{lll}
\frac{W^{H}-W^{L}}{c_{N L}^{2}} \leq & \hat{s^{2}}< & \frac{W^{H}-W^{L}}{c_{T H}^{2}} \\
\frac{W^{H}-W^{L}}{c_{N L}^{2}} \leq & \hat{s^{2}}< & \frac{W^{H}-W^{L}}{c_{N H}^{2}} \\
\frac{W^{H}-W^{L}}{c_{T L}^{2}} \leq & \hat{s^{2}}< & \frac{W^{H}-W^{L}}{c_{T H}^{2}} \\
\frac{W^{L}-W^{H}}{c_{N H}^{2}}< & \hat{s^{2}} \leq & \frac{W^{L}-W^{H}}{c_{T L}^{2}} .
\end{array}
$$

As $c_{N L}^{2}$ is always the largest marginal cost, the first two always hold. As $c_{T H}^{2}$ is always the smallest marginal cost, the third always holds. This leaves the fourth as the only necessary inequality. We can multiply through by -1 to get: $\frac{W^{H}-W^{L}}{c_{T L}^{2}} \leq \hat{s^{2}}<\frac{W^{H}-W^{L}}{c_{N H}^{2}}$. This holds whenever $c_{T L}^{2}>c_{N H}^{2}$, as it does in option (X2). It does not hold in option (X1). Thus, in option (X2) we can find a semi-separating equilibrium in which the dictator can use the subordinate's signal to separate those of high disposition from those of low disposition, with no information as to subordinate belief revealed. Under this option, high disposition types play $\hat{s^{2}}=\frac{W^{H}-W^{L}}{c_{T L}^{2}}$ and low disposition types play 0 .

In option (X1), in contrast, there can be no such separation, so we must look for a different equilibrium. The reason the equilibrium that worked under (X2) fails under (X1) is that type $T L$ has incentive to pretend to be type $N H$ under (X1). As we cannot separate types $T L$ and $N H$ for this reason, the most informative equilibrium pools the behavior of both of these types.

We let $W^{M}=\frac{p_{T L} W_{T L}}{p_{T L}+p_{N H}}+\frac{p_{N H} W_{N H}}{p_{T L}+p_{N H}}$; this is the expected benefit to a subordinate under a lottery in which she could be slotted into either of two roles, with probability equal to the dictator's posterior beliefs about the likelihood of each role given an equilibrium that pools across both roles. This implies $W_{T H}>W^{M}>W_{N L}$. To save some effort, we will without loss of generality set $W_{N L}=0$. This implies that $s_{T H}^{2}>\left(s^{2}\right)^{M}>s_{N L}^{2}=0$. Inequalities (1)-(6) become

$$
\begin{aligned}
& \frac{W_{T H}}{c_{N L}^{2}} \leq \quad s_{T H}^{2}<\quad \frac{W_{T H}}{c_{T H}^{2}}, \\
& \frac{W^{M}}{c_{N L}^{2}} \leq \quad\left(s^{2}\right)^{M}<\quad \frac{W^{M}}{c_{T L}^{2}}, \\
& \frac{W^{M}}{c_{N L}^{2}} \leq \quad\left(s^{2}\right)^{M}<\quad \frac{W^{M}}{c_{N H}^{2}}, \\
& \frac{W_{T H}-W^{M}}{c_{T L}^{2}} \leq \quad s_{T H}^{2}-\left(s^{2}\right)^{M}<\quad \frac{W_{T H}-W^{M}}{c_{T H}^{2}} \text {, } \\
& \frac{W_{T H}-W^{M}}{c_{N H}^{2}} \leq \quad s_{T H}^{2}-\left(s^{2}\right)^{M}<\quad \frac{W_{T H}-W^{M}}{c_{T H}^{2}} \text {. }
\end{aligned}
$$

${ }^{4}$ Here $W^{H}=W_{T H}=W_{N H}$ and $W^{L}=W_{T L}=W_{N L}$, but we keep the analysis more general so as be able to reuse it later. 
Though there are five inequalities, since $c_{T L}^{2}<c_{N H}^{2}$ under option (X1), only (7), (9), and (10) bind.

All five inequalities are possible on their own, but we still must check that they are consistent together and do not specify contradictory bounds for the differences between the signals. The reason we need to do this is that sums and differences of some inequalities offer competing sets of bounds for the same differences between signals.

(7) together with [9] implies $\frac{W_{T H}}{c_{N L}^{2}}-\frac{W^{M}}{c_{N H}^{2}}<s_{T H}^{2}-\left(s^{2}\right)^{M}<\frac{W_{T H}}{c_{T H}^{2}}-\frac{W^{M}}{c_{N L}^{2}}$. We'll first compare this to 11 , which doesn't bind. Because $\frac{W_{T H}}{c_{N L}^{2}}-\frac{W^{M}}{c_{N H}^{2}}-\frac{W_{T H}-W^{M}}{c_{N H}^{2}}=\frac{W_{T H}\left(c_{N H}^{2}-c_{N L}^{2}\right)}{c_{N H}^{2} c_{N L}^{2}}<0$, the LHS of 11 , is a stricter bound than the LHS of (7) with (9). Because the LHS of $(10)$ is stricter still, the LHS of the inequalities are consistent. Similarly, because $\frac{W_{T H}}{c_{T H}^{2}}-\frac{W^{M}}{c_{N L}^{2}}-\frac{W_{T H}-W^{M}}{c_{T H}^{2}}=\frac{W^{M}\left(c_{N L}^{2}-c_{T H}^{2}\right)}{c_{T H}^{2} c_{N L}^{2}}>0$, the RHS of (10) is a stricter bound than the RHS of (7)-(9). So the bounds of (10) are contained in those of (7) with (9), our inequalities are consistent, and we have a semi-separating equilibrium with $s_{N L}^{2}=0,\left(s^{2}\right)^{M}=\frac{W^{M}}{c_{N L}^{2}}$, and $s_{T H}^{2}=\frac{W_{T H}}{c_{T L}^{2}}-\frac{W^{M}\left(c_{N L}^{2}-c_{T L}^{2}\right)}{c_{T L}^{2} c_{N L}^{2}}$.

\section{Options A and B}

Either $W_{T H}>W_{T L}>W_{N H}>W_{N L}(\mathrm{~A})$ or $W_{T H}>W_{N H}>W_{T L}>W_{N L}(\mathrm{~B})$.

We'll start with (A). Under this option, regardless of the ordering of the marginal costs, inequalities (1)-(5) all hold individually as long as $s_{T H}^{2}>s_{T L}^{2}>s_{N H}^{2}>s_{N L}^{2}$. Under option (A1), $c_{T L}^{2}<c_{N H}^{2}$ and (6) holds as well, while under option (A2), (6) does not hold. This implies that no fully separating equilibrium is possible in the case of option (A2). Before moving on to finding a different equilibrium in this case, though, we first must make sure that (1)-(6) can hold simultaneously under (A1).

Without loss of generality, set $W_{N L}=s_{N L}^{2}=0$. Combining (1) through (3) produces the following three equations:

$$
\begin{array}{lll}
\frac{W_{T H}}{c_{N L}^{2}}-\frac{W_{T L}}{c_{T L}^{2}} \leq & s_{T H}^{2}-s_{T L}^{2}< & \frac{W_{T H}}{c_{T H}^{2}}-\frac{W_{T L}}{c_{N L}^{2}}, \\
\frac{W_{T H}}{c_{N L}^{2}}-\frac{W_{N H}}{c_{N H}^{2}} \leq & s_{T H}^{2}-s_{N H}^{2}< & \frac{W_{T H}}{c_{T H}^{2}}-\frac{W_{N H}}{c_{N L}^{2}}, \\
\frac{W_{T L}}{c_{N L}^{2}}-\frac{W_{N H}}{c_{N H}^{2}} \leq & s_{T L}^{2}-s_{N H}^{2}< & \frac{W_{T L}}{c_{T L}^{2}}-\frac{W_{N H}}{c_{N L}^{2}} .
\end{array}
$$

Comparing these to (4)-(6), we see that the bounds of (4) are contained within those of (12), those of (5) are contained within those of (13), and those of (6) are contained within those of (14). This implies that (1)-(3) are consistent with (4)-(6).

All that's left is to show that (4)-(6) are consistent. We start by adding (4) to (6). This yields $\frac{W_{T H}}{c_{T L}^{2}}-\frac{W_{T L}}{c_{T L}^{2}}+\frac{W_{T L}}{c_{N H}^{2}}-\frac{W_{N H}}{c_{N H}^{2}} \leq s_{T H}^{2}-s_{N H}^{2}<\frac{W_{T H}}{c_{T H}^{2}}-\frac{W_{T L}}{c_{T H}^{2}}+\frac{W_{T L}}{c_{T L}^{2}}-\frac{W_{N H}}{c_{T L}^{2}}$. This produces an alternative set of bounds for the difference $s_{T H}^{2}-s_{N H}^{2}$ to that given in (5). Compare the LHS of each of these bounds first. Because $\frac{W_{T H}}{c_{T L}^{2}}-\frac{W_{T L}}{c_{T L}^{2}}+\frac{W_{T L}}{c_{N H}^{2}}-\frac{W_{N H}}{c_{N H}^{2}}-\frac{W_{T H}-W_{N H}}{c_{N H}^{2}}=\frac{\left(W_{T H}-W_{T L}\right)\left(c_{N H}^{2}-c_{T L}^{2}\right)}{c_{N H}^{2} c_{T L}^{2}}>0$ for option (A1), the LHS of (4) $+(\sqrt{6})$ is a stricter bound than the LHS of (5). Similarly, because $\frac{W_{T H}}{c_{T H}^{2}}-\frac{W_{T L}}{c_{T H}^{2}}+\frac{W_{T L}}{c_{T L}^{2}}-\frac{W_{N H}}{c_{T L}^{2}}-\frac{W_{T H}-W_{N H}}{c_{T H}^{2}}=\frac{\left(W_{T L}-W_{N H}\right)\left(c_{T H}^{2}-c_{T L}^{2}\right)}{c_{T H}^{2} c_{T L}^{2}}<0$ for option (A1), the RHS of (4) $+(6)$ is a stricter bound than the RHS of (5). Consequently, we can eliminate (5) from our system of inequalities.

Put together, equations (1)-(4) and (6) provide a consistent set of inequalities specifying the 
bounds of our equilibrium signals. With $W_{N L}=s_{N L}^{2}=0$, the other three signals are $s_{N H}^{2}=\frac{W_{N H}}{c_{N L}^{2}}$, $s_{T L}^{2}=\frac{W_{T L}}{c_{N H}^{2}}-\frac{W_{N H}\left(c_{N L}^{2}-c_{N H}^{2}\right)}{c_{N H}^{2} c_{N L}^{2}}$, and $s_{T H}^{2}=\frac{W_{T H}}{c_{T L}^{2}}-\frac{W_{N H}\left(c_{N L}^{2}-c_{N H}^{2}\right)}{c_{N H}^{2} c_{N L}^{2}}-\frac{W_{T L}\left(c_{N H}^{2}-c_{T L}^{2}\right)}{c_{N H}^{2} c_{T L}^{2}}$. This defines a fully separating PBE under option (A1).

We'll put off option (A2) a bit longer, instead addressing (B). The analysis is very similar to (A). Inequalities (1)-(5) remain true regardless of the marginal cost ordering, as long as $s_{T H}^{2}>s_{N H}^{2}>s_{T L}^{2}>s_{N L}^{2}$. With $W_{N H}>W_{T L}$, (6) becomes $\frac{W_{N H}-W_{T L}}{c_{T L}^{2}} \leq s_{N H}^{2}-s_{T L}^{2}<\frac{W_{N H}-W_{T L}}{c_{N H}^{2}}$. Under option (B1), $c_{T L}^{2}<c_{N H}^{2}$ and (6) does not hold, while under option (B2), (6) holds. This implies that no fully separating equilibrium is possible in the case of option (B1). We'll group this with (A2) and first make sure that (1)-(6) can hold simultaneously in (B2).

Most of the same analysis as in (A1) holds in (B2) unchanged. All we need to do is compare (5) $+(6)$ to (4). Again setting $W_{N L}=s_{N L}^{2}=0$, we get that the sum (5) $+\sqrt{6}$ is $\frac{W_{T H}}{c_{N H}^{2}}-\frac{W_{N H}}{c_{N H}^{2}}+$ $\frac{W_{N H}}{c_{T L}^{2}}-\frac{W_{T L}}{c_{T L}^{2}} \leq s_{T H}^{2}-s_{T L}^{2}<\frac{W_{T H}}{c_{T H}^{2}}-\frac{W_{N H}}{c_{T H}^{2}}+\frac{W_{N H}}{c_{N H}^{2}}-\frac{W_{T L}}{c_{N H}^{2}}$. This produces an alternative set of bounds for the difference $s_{T H}^{2}-s_{T L}^{2}$ to that given in (4). Compare the LHS of each of these bounds first. Because $\frac{W_{T H}}{c_{N H}^{2}}-\frac{W_{N H}}{c_{N H}^{2}}+\frac{W_{N H}}{c_{T L}^{2}}-\frac{W_{T L}}{c_{T L}^{2}}-\frac{W_{T H}-W_{T L}}{c_{T L}^{2}}=\frac{\left(W_{T H}-W_{N H}\right)\left(c_{T L}^{2}-c_{N H}^{2}\right)}{c_{N H}^{2} c_{T L}^{2}}>0$ for option (B2), the LHS of (5) $+(\sqrt{6)}$ is a stricter bound than the LHS of (4). Similarly, because $\frac{W_{T H}}{c_{T H}^{2}}-\frac{W_{N H}}{c_{T H}^{2}}+\frac{W_{N H}}{c_{N H}^{2}}-\frac{W_{T L}}{c_{N H}^{2}}-\frac{W_{T H}-W_{T L}}{c_{T H}^{2}}=\frac{\left(W_{N H}-W_{T L}\right)\left(c_{T H}^{2}-c_{N H}^{2}\right)}{c_{T H}^{2} c_{N H}^{2}}<0$ for option (B2), the RHS of (5) $+(6)$ is a stricter bound than the RHS of (4). Consequently, we can eliminate (4) from our system of inequalities.

Put together, equations (1)-(3) and (5)-(6) provide a consistent set of inequalities specifying the bounds of our equilibrium signals. With $W_{N L}=s_{N L}^{2}=0$, the other three signals are $s_{T L}^{2}=\frac{W_{T L}}{c_{N L}^{2}}$, $s_{N H}^{2}=\frac{W_{N H}}{c_{T L}^{2}}-\frac{W_{T L}\left(c_{N L}^{2}-c_{T L}^{2}\right)}{c_{T L}^{2} c_{N L}^{2}}$, and $s_{T H}^{2}=\frac{W_{T H}}{c_{N H}^{2}}-\frac{W_{T L}\left(c_{N L}^{2}-c_{T L}^{2}\right)}{c_{T L}^{2} c_{N L}^{2}}-\frac{W_{N H}\left(c_{T L}^{2}-c_{N H}^{2}\right)}{c_{N H}^{2} c_{T L}^{2}}$. This defines a fully separating PBE under option (B2).

Now we turn finally to (A2) and (B1). The only thing preventing a fully separating equilibrium under these two options is the inability to separate type $T L$ from type $N H$. In both cases, the dictator cannot prevent the lower compensated type from pretending to be the higher compensated type. The next-most informative equilibrium would be one in which these two types pool, but the other two types separate. Even though this is less informative than the fully separating case, the dictator still learns the type of the dictator's most preferred subordinate.

This PBE is the same as that analyzed under option (A1). Option (B1) has exactly the same analysis, which we do not repeat. Option (A2), with $c_{T L}^{2}>c_{N H}^{2}$, has a different set of inequalities bind: (7), (8), and (11). As before, we need only check the consistency of these three inequalities. Further, because the RHS check is identical to that performed under (A1), we need only check the LHS.

We compare (7) with (8) to 10 , which is less strict than 11, As $\frac{W_{T H}}{c_{N L}^{2}}-\frac{W^{M}}{c_{T L}^{2}}-\frac{W_{T H}-W^{M}}{c_{T L}^{2}}=$ $\frac{W_{T H}\left(c_{T L}^{2}-c_{N L}^{2}\right)}{c_{T L}^{2} c_{N L}^{2}}<0$, the LHS of 10 is a stricter bound than the LHS of 7 with 8 . Because the LHS of (11) is stricter still, the LHS of the inequalities are consistent. So we have a semiseparating equilibrium in both (B1) and (A2), with the same equilibrium signals as in (A1) for (B1) and the following slightly different equilibrium signals for (A2): $s_{N L}^{2}=0,\left(s^{2}\right)^{M}=\frac{W^{M}}{c_{N L}^{2}}$, and $s_{T H}^{2}=\frac{W_{T H}}{c_{N H}^{2}}-\frac{W^{M}\left(c_{N L}^{2}-c_{N H}^{2}\right)}{c_{N H}^{2} c_{N L}^{2}}$.

\section{Option C}

In option $\mathrm{C}$, either $W_{N H}>W_{T H}>W_{N L}>W_{T L}(\mathrm{Ci})$ or $W_{N H}>W_{N L}>W_{T H}>W_{T L}$ (Cii). In either case, our incentive compatibility constraints do not all hold. Specifically, (2) and (5) never 
hold, (1) only holds in (Ci), (3) and (4) always hold, and (6) only holds in (Ci2) and (Cii2). This implies that there are no fully-separating equilibria under option (C).

The semi-separating equilibria are also more constrained than under the previous two options. Most relevantly, no PBE exists that signals only the dictator's most preferred type, as there is always at least one other type with lower cost who would have incentive to mimic type $N H$. This means there is always a chance that less preferred types end up in the regime's most important positions under option (C). One can also not separate type $N L$ from $T L$, for a similar reason.

We begin with (Ci2). This option is most similar to (A2), in that if the dictator's two most preferred types pool on a higher signal and the two least preferred types pool on a lower one then the incentive compatibility constraints will hold. Thus, under (Ci2) we posit the identical $\mathrm{PBE}$ as given under (A2), and all the same analysis applies. Note that this outcome is worse for the dictator than it was under option (A2) since now the dictator prefers no belief types to true believers and is forced to tolerate the chance that the latter will occupy the most important regime positions, but it is the best the dictator can do.

Now turn to (Ci1). The above PBE for (Ci2) does not apply for the same reasons it didn't for (A1). As under (A1), the option to get around this by pooling $N H$ and $T L$ is available. Unlike under (A1), though, this option may not be possible. Let $W^{M}=\frac{p_{T L} W_{T L}}{p_{T L}+p_{N H}}+\frac{p_{N H} W_{N H}}{p_{T L}+p_{N H}}$, as above. If $W_{T H} \geq W^{M} \geq W_{N L}$, then an identical equilibrium to that given in (A1) holds. ${ }^{5}$

If $W_{N L}>W^{M}$, there is incentive for types $N H$ and $T L$ to deviate to $s_{N L}^{2}=0$ and so this is not an equilibrium. Let $W^{-}=\frac{p_{T L} W_{T L}}{p_{T L}+p_{N H}+p_{N L}}+\frac{p_{N H} W_{N H}}{p_{T L}+p_{N H}+p_{N L}}+\frac{p_{N L} W_{N L}}{p_{T L}+p_{N H}+p_{N L}}$. As long as $W_{T H} \geq W^{M}$ then $W_{T H} \geq W^{-}$as well, since $W_{T H}>W_{N L}$ in $(\mathrm{Ci})$. In this case we can form a $\mathrm{PBE}$ in which all types but $T H$ pool on 0 . The sole binding incentive compatibility constraint here is $\frac{W_{T H}-W^{-}}{c_{T L}^{2}} \leq s_{T H}^{2}<\frac{W_{T H}-W^{-}}{c_{T H}^{2}}$ which always holds under these assumptions. Here the equilibrium signal for $T H$ is $s_{T H}^{2}=\frac{W_{T H}-W^{-}}{c_{T L}^{2}}$.

If $W^{M} \geq W_{N L}$, then there is incentive for type $T H$ to deviate to $\left(s^{2}\right)^{M}$ to secure $W^{M}$ and so this is not an equilibrium. Let $W^{+}=\frac{p_{T L} W_{T L}}{p_{T L}+p_{N H}+p_{T H}}+\frac{p_{N H} W_{N H}}{p_{T L}+p_{N H}+p_{T H}}+\frac{p_{T H} W_{T H}}{p_{T L}+p_{N H}+p_{T H}}$. As long as $W^{M} \geq W_{N L}$ then $W^{+} \geq W_{N L}$, since $W_{T H}>W_{N L}$ in $(\mathrm{Ci})$. In this case we can form a PBE in which all types but $N L$ pool on $s$ and $N L$ makes signal 0 . The sole binding incentive compatibility constraint here is $\frac{W^{+}-W_{N L}}{c_{N L}^{2}} \leq \tilde{s^{2}}<\frac{W^{+}-W_{N L}}{c_{N H}^{2}}$ which always holds under these assumptions. Here the equilibrium signal for the three pooled types is $\tilde{s^{2}}=\frac{W^{+}-W_{N L}}{c_{N L}^{2}}$. Since it is not possible for both $W_{T H}<W^{M}$ and $W_{N L}>W^{M}$ in $(\mathrm{Ci})$, we have fully characterized the PBE under this option.

Next turn to (Cii). The problem for the dictator here is that any proposed equilibrium that specifies a non-minimal signal for type $N L$ provides incentive for all other types to pool with $N L$ if they aren't receiving in expectation greater than the level of benefits $N L$ receives. This implies that not only can we not have an equilibrium in which the dictator's top choice, $N H$, can separate out, but also no PBE in which the dictator's second choice, $N L$, can separate out. This leaves only a few possibilities.

Start with (Cii2). Because $c_{T L}^{2}>c_{N H}^{2}$ here, we can separate the corresponding types. The same PBE as under ( $\mathrm{Ci2}$ ) is possible if $W^{H} \geq W^{L}$. This will sometimes be true, but not always. If it is not true, then this PBE will not hold. We can then try the same PBE as in (Ci1) in which all types but $N L$ or $T H$ pool. If $W^{+} \geq W_{N L}$ then a PBE exists in which all types but

${ }^{5}$ We are free to set $W_{N L}=0$ even though here this implies $W_{T L}<0$; however, we could also forgo this and simply replace $W_{T H}$ with $W_{T H}-W_{N L}$ and $W^{M}$ with $W^{M}-W_{N L}$ in (7)-(9). 
$N L$ pool, as above. If $W_{T H} \geq W^{-}$then a PBE exists in which all types but $T H$ pool. We note that both conditions are more difficult to meet here, as $W_{N L}$ is relatively greater than before. If neither of these conditions hold, then no type can be separated and we are left with only a pure pooling $\mathrm{PBE}$, in which all types make signal 0 and expected benefits to all subordinates are $W^{P}=p_{T H} W_{T H}+p_{N H} W_{N H}+p_{T L} W_{T L}+p_{N L} W_{N L}$.

Finally, consider (Cii1). We can no longer separate $T L$ from $N H$ because $c_{T L}^{2}<c_{N H}^{2}$ here, so we do not have the PBE with $W^{H}$ and $W^{L}$ available. The rest of the analysis as under (Cii2) continues to hold though, and this specifies the range of equilibria possible under this option.

\section{Online Appendix B: Robustness and model extensions}

Our model's conclusions and key insights rest on a handful of assumptions. Here we briefly discuss the degree to which they drive our results and the robustness of these results to variation in assumptions.

Our first key insight, that one can separate signals of skill-based competence from signals of belief and disposition-based competence, was driven by the existence of observable implications of subordinate skill different from behavior within the cult. Although we believe this to be generally true, we can consider what would happen if no such skill-related signal existed. The dictator would have two ways of dealing with this. One would be to not distinguish between separate aspects of competence at all. In other words, treat important subordinate traits as two-dimensional, with belief on one dimension and competence on the other. Our results are unchanged in this case, save that the dictator has no way of distinguishing between different aspects of competence. A second way would be to try to discern skills as well, only without the additional signal. Full information revelation about subordinate type remains possible, but now would require the payoff ordering over the middle six types to match these types' marginal costs of extreme behavior within the cult. It seems likely that this would fail to occur, leading to different types pooling on their signals in potentially complex ways. However, careful screening mechanisms of the type we describe below might allow a more positive outcome for the dictator.

Our second insight, that the dictator can perfectly discern the subordinates' types, relies on the ordering of the subordinates' payoffs matching that of their marginal costs. This can fail when types in the middle ( $T L$ and $N H$ ) fail to align, as discussed above. But it can also fail when the dictator is indifferent between types, or when the dictator prefers a lower type to a higher one. Indifference can happen, for example, when belief does not correlate with loyalty or loyalty is not needed for a role. We think both of these scenarios are unlikely. Preferring a lower type, as discussed in the text's footnotes 12 and 13, can happen, for example, when belief is correlated with not just a lack of skill (the model accounts for this) but also other characteristics that negatively correlate with regime survival. We don't believe this to be a common occurrence, empirically-speaking. After all, loyalty is essential for regime survival, as is dispositional competence, and we allow skill-based competence to correlate in either direction with belief and dispositional competence. Further, our previous results are entirely robust to the presence of negative correlates of belief, up until the point at which they outweigh the benefits of belief-induced loyalty.

With that being said, we analyze models that allow for indifference and negative traits in online appendix A. In doing so we assume that the trait in question is belief and drop the separable skill dimension for simplicity. The analysis would go through identically if this trait were disposition. As might be expected, the dictator does worse, often substantially so, in these circumstances. When the dictator is indifferent with respect to belief, he is able to perfectly select competent subordinates as long as the payoffs and costs of the middle types line up as before; however, even in this case he cannot distinguish along the dimension of belief. This is not immediately problematic 
as belief is assumed to be unimportant to him in this case. However, should this change in the future, the dictator will be poorly equipped to take advantage of the change, since roles within the regime will not be sorted by belief, and therefore not by loyalty.

If belief is a net negative trait the dictator fares far worse. The issue is that the dictator now strictly prefers non-believing subordinates who pay higher costs for extreme behavior. This renders the cult of personality far less effective. At best, if the payoff and marginal cost orderings align just right, he can separate high competence types from low competence types. This still leads to the use of disliked believers, though, in the most important jobs. At worst, all subordinate types pool on the same signal and the dictator cannot distinguish anyone. In between, there are cases in which two or three types of subordinate pool on the same signal. Regardless of which case holds, two things are true: the dictator never learns all type-specific information, and he can never separate out his most preferred type, $N H$. Together, what this means is that the cult fails the dictator in an important way: regardless of the arrangement of parameters, there is always a chance that the dictator will end up with a non-preferred true-believer in the most important regime roles. This is not to say that the dictator does not benefit from the cult of personality even given belief as a negative trait, in that in all but the worst case scenario he does better than if the cult were absent. But not preferring belief misaligns the incentives of the subordinates with their costs of taking action, inducing true believers to mimic other types and secure more important roles.

Even if belief (or disposition-based competence) is viewed as a negative by the dictator, however, he still has tools at his disposal. We have assumed thus far that the payoffs to the subordinate for each role are exogenously fixed. In practice, though, the dictator may have some leeway to adjust payoffs at the same time he constructs his cult. Formally, this amounts to construing our strategic interaction as a screening game, with an extra stage in advance of the two stages we model. In such a screening game, in stage zero the dictator sets payoffs. Then the subordinate signals type and the dictator slots him into a role, as before.

If the dictator is unconstrained in the payoff ordering he provides in stage zero, our analysis clearly indicates that this screening game will produce the best outcome for him: subordinates will perfectly signal their type and the dictator will optimally slot them into roles. Thus, an unconstrained dictator will construct a perfectly useful cult in the initial, screening stage, which will eliminate his adverse selection problem. Importantly, this solution does not only work when belief (or disposition-based competence) serves as a negative trait; it also functions in the less detrimental case in which all traits are beneficial but the middle types of subordinate would otherwise pool on a single signal, making them indistinguishable.

Given the power of this screening stage, what, then, would stop the dictator from using it successfully? The answer is that this type of screening requires a commitment on the part of the dictator to ordering subordinates' payoffs according to their types rather than their worth to him. First, this requires a credible commitment from the dictator, who would have incentives to renege on any agreed-upon reward after the subordinate's task is completed in the absence of an external enforcement mechanism to bind his hands. Repeated interactions are not generally sufficient to solve this problem since a dictator's time horizon will be short when faced with internal or external challenges (North and Weingast 1989; Haber, Razo, and Maurer 2003: 18-40).

Second, using a screening stage requires that the dictator actually prefers to make such a commitment, as we noted briefly in the text's footnote 17. Committing to provide rewards in excess of those typically associated with a regime role entails "overpaying" for the services of the subordinate. Screening only operates as an equilibrium if the marginal benefit of slotting the subordinate into his optimal role is at least as great as the overpayment needed to do so. We expect this to be true, suggesting more of a role for screening, under a couple of common circumstances. 
One, if the dictator can devise tailor-made roles that minimize the negative aspects of certain traits, he would be forced into minimal overpayment when providing well-rewarded roles for less-preferred subordinate types. For example, propagandist and biographer roles both would make excellent use of a true believer and not be appreciably affected by most other negative correlates of belief. Similarly, detrimentally unscrupulous subordinates could be sent on assassination missions abroad. Two, if monetary or other fungible rewards were available, the dictator could merely pay off true believers (or unscrupulous types) over and above the payoffs they received from their roles, allowing him to minimize overpayment.

In contrast, if such roles were not available or their availability had been exhausted, and monetary rewards were also not available, the cost of overpayment would need be borne by the greater rewards inherent in more important roles, producing a greater cost to the dictator from screening. In this circumstance, we would expect less use of screening, all else equal. That said, we do not view this circumstance as particularly likely when the only mismatch involves the middle two types, as in the text; thus, we expect screening to enhance our earlier results.

In sum, relaxing our key assumptions does not void our primary result about the utility of a cult of personality, and a simple model extension to include a screening stage returns the cult to its strongest benefit under a wide variety of circumstances.

\author{
Additional references
}

North, Douglass C. and Barry R. Weingast. 1989. "Constitutions and commitment: the evolution of institutions governing public choice in seventeenth-century England." Journal of Economic History 49 (4): 803-832.

Haber, Stephen, Armando Razo, and Noel Maurer. 2003. The politics of property rights. Cambridge University Press. 